\title{
Review
}

\section{Non-destructive technologies for fruit and vegetable size determination - A review}

G.P. Moreda

, J. Ortiz-Cañavate , F.J. García-Ramos and M. Ruiz-

\section{Altisent}

Departamento de Ingeniería Rural, Universidad Politécnica de Madrid, 28040 Madrid, Spain

Escuela Politécnica Superior de Huesca, Universidad de Zaragoza, 22071 Huesca, Spain

\begin{abstract}
Here, we review different methods for non-destructive horticultural produce size determination, focusing on electronic technologies capable of measuring fruit volume. The usefulness of produce size estimation is justified and a comprehensive classification system of the existing electronic techniques to determine dimensional size is proposed. The different systems identified are compared in terms of their versatility, precision and throughput. There is general agreement in considering that online measurement of axes,
\end{abstract}


perimeter and projected area has now been achieved. Nevertheless, rapid and accurate volume determination of irregular-shaped produce, as needed for density sorting, has only become available in the past few years. An important application of density measurement is soluble solids content (SSC) sorting. If the range of SSC in the batch is narrow and a large number of classes are desired, accurate volume determination becomes important. A good alternative for fruit three-dimensional surface reconstruction, from which volume and surface area can be computed, is the combination of height profiles from a range sensor with a two-dimensional object image boundary from a solid-state camera (brightness image) or from the range sensor itself (intensity image). However, one of the most promising technologies in this field is 3-D multispectral scanning, which combines multispectral data with 3-D surface reconstruction.

Keywords: Dimensional measurement; Fruit; Grading; Machine vision; Postharvest; Size; Sorter; Volume

Abbreviations: $\mathrm{CCD}$, charge-coupled device; CMOS, complementary metal oxide semiconductor; CSM, charge-simulation method; CT, computed tomography; $\mathrm{CV}$, coefficient of variation; EC, European Communities; IQ, internal quality; LED, light emitting diode; MAE, mean absolute error; MAPE, mean absolute percentage error; MRI, magnetic resonance imaging; NIR, near-infrared; RMSE, root mean squared error; RMSPE, root mean squared percentage error; SSC, soluble-solids content; TOF, time of flight; VI, volume intersection; 2-D, two-dimensional; 3-D, three-dimensional 


\section{Introduction}

The fresh fruit and vegetable postharvest sector is dynamic, due largely to increasing consumer demand for quality produce (Aleixos et al., 2002). This, together with the fact that machines are more consistent than humans (Deck et al., 1995; Njoroge et al., 2002; Aleixos et al., 2002), the scarceness of labor in developed countries (Walsh, 2005), and the opportunity to reduce labor costs (Bato et al., 2000), has led to remarkable mechanization and automation in packinghouses during the past few decades. In the past few years, several authors have reviewed the main advances in this field. Studman (2001) reviewed the operations in the postharvest industry, where computers and electronic technologies have had a huge impact. Brosnan and Sun (2004) compared different computer vision systems for horticultural produce blemish and disease detection. García-Ramos et al. (2005) reviewed state-of-the-art non-destructive fruit firmness sensors. Butz et al. (2005) and Nicolai et al. (2006) compared different technologies to characterize the internal quality (IQ) of fruits and vegetables.

Although it is now established that IQ assessment has an important role in the fruit and vegetable postharvest stage, the external appearance of fresh produce will continue to be an important factor, and an important aspect of external appearance is fruit size; the reasons why fruit size is important are outlined in Section 2. The aim of this paper is to review different modern approaches to measure the size of horticultural produce; in particular electronic systems capable of non-destructively determining produce dimensional size. To our knowledge, the last synthesis paper dealing with size determination was that by Affeldt et al. (1994). There have been many new developments since then, highlighting the need for an updated review.

This document is organized as follows: Section 2 outlines the need for measuring fruit size; Section 3 compares mechanical and electronic sizers; Section 4 provides some background information on weight sizers; Section 5 addresses the problems associated with reference laboratory instruments for volume measurement; Section 6, the core of the paper, classifies and compares the different dimensional measurement systems (a withingroup comparison is performed for some groups, whereas for others, a between-group comparison is performed); Section 7 presents the conclusions; finally, Section 8 is an Appendix that outlines the basic statistical mentioned throughout the paper.

\section{Interest of horticultural produce size determination}

Fruit size can be expressed in terms of parameters such as volume, weight, and diameter; a detailed description of sizing parameters is included in Section 3. In terms of fruit volume, in-the-field non-destructive estimates of this parameter can be used as a ripeness index to predict optimum harvest time (Hahn and Sanchez, 2000), predict yield (Mitchell, 1986), or to study the relationship between fruit expansion rate and susceptibility to physiological disorders such as fruit cracking (Ngouajio et al., 2003).

In the context of postharvest operations, fruit size determination is important for several reasons.

- It allows the sorting of fresh market fruits into size groups. This is convenient to assign market and price differentials of large and small produce, to match consumer preferences (most con- sumers prefer fruit classified into batches of uniform size), and probably most important, to allow pattern packing. The advantage of pattern packs over jumble packs is that they provide better protection of the produce (Peleg, 1985a). Moreover, pattern packages better utilizes the volume in the shipping container, owing to the higher packing density that can be achieved with this type of packaging (Studman, 1999). Peleg (1985a) and Miller (1992), based on geometric analysis and on experimental tests, showed that the packing density for a jumble pack of oranges was $60 \%$, whereas the packing density for a pattern pack configuration such as the so-called face-centered cubic configuration was $74 \%$.

- Size determination is mandatory for modern or 'dry' on-line fruit density sorting, for which two size-related parameters, volume and weight, are required. ${ }^{1}$ Fruit density sorting is useful for two reasons. First, in many species fruit density and soluble-solids content (SSC) are correlated (Ting and Blair, 1965; Sugiura et al., 2001; Jordan and Clark, 2004); in addition, potato tuber density and starch content are also correlated (Hoffmann et al., 2004). Second, density determination is important for separating, for example, freeze-damaged citrus fruits (Wardowski et al., 1998), fruits that have undergone natural internal desiccation (Miller, 1993), puffy tangerines (Aleixos, 1999), fruits with internal damage caused by insects (Forbes and Tattersfield, 1999a), watermelons with a high degree of hollowness (Kato, 1997), and apples affected by watercore (Throop et al., 1989). Differences in density between fruits of the same cultivar with different SSC are usually very small (Jordan and Clark, 2004). Therefore, a high level of accuracy is required in density measurement if the fruits are to be sorted by SSC based on density. If the range of SSC in the batch is narrow and a high number of classes are desired, accurate volume determination becomes critical. Miller et al. (1988) performed an error analysis based on the square error propagation law (also known as root-sum-square formula; Doebelin, 1966) to determine required dimensional and weight accuracy for a $1 \%$ density accuracy. Assuming a perfectly spherical citrus fruit with an average diameter of $100 \mathrm{~mm}$ and a mass of $450 \mathrm{~g}$ (density = $0.859 \mathrm{~g} / \mathrm{ml}$ ), and equal error contributions of mass and volume, they found that, for a $1 \%$ root mean square (RMS) density accuracy, mass, volume, and diameter accuracies of $3.2 \mathrm{~g}, 3.7 \mathrm{ml}$, and $0.24 \mathrm{~mm}$, respectively, were required. Dividing the mass and volume accuracies by their respective mean values results in a root mean squared percentage error (RMSPE) of $0.7 \%$ in each case. Hoffmann et al. (2004) and Hoffmann et al. (2005), stated that for high quality cooked potatoes it is necessary to classify the single tubers into different starch categories before cooking. For on-line sorting of potato tubers according to their starch content, these researchers used a previously developed linear relationship between starch content and tuber density. Owing to the law of square error propagation, they stated that a 1\% RMSPE of mass and volume was required for classifying the tubers into three starch classes, each with a class width of $6 \%$.

- Size measurement is important for determining produce surface area. The latter is also of use for quantifying the microbial population on the surface of a foodstuff (Eifert et al., 2006), for

\footnotetext{
1 Fruit density sorting can also be achieved in a traditional or 'wet way', through differences in flotation; in this case fruit size estimation is not necessary.
} 
assessing the rates of heat, water vapor and gas transfer (Clayton et al., 1995), or for estimating the throughput of peeling operations (Wright et al.,1986).

- Fruit size can provide useful information for suitable working of some IQ sensors. For instance, in packing lines where brix sensing is performed, it is common to position a size sensor upstream of the near infrared (NIR) spectrophotometer to allow adjustment of the NIR head height according to fruit size (W. Miller, personal communication, 15 November 2003). Likewise, the size and position of fruits traveling on a conveyor system may be evaluated prior to firmness testing, thereby eliminating false firmness measurements due to improper fruit position in the firmness sensor (Peleg, 1995).

- Grading of fruits into size groups is often necessary in the food industry, to meet the requirements of some processing machines, or to assign process differentials of large and small produce. For example, extractors in citrus juice plants are usually designed for a given fruit size. Peeling machines in artichoke canning factories require correctly sized vegetables for working. In the peach canning industry, fruit must be size-graded to accommodate the pitting machines. Peaches that are too small to be halved, quartered, or sliced, are processed into concentrate.

- According to Du and Sun (2004), shape features can be measured independently (for example, by Fourier descriptors of the planar image boundary, invariant moments) or by combining size measurements (for example, circularity, aspect ratio, compactness, eccentricity, roundness). Hence, the determination of fruit size parameters allows simple shape sorting.

\section{Definition of sizing. Types of sizers. Sizing parameters}

Peleg (1985a) defined sizing as separating produce into size groups, that is, sorting by size. Mattone et al. (2000), studying recyclable packaging, stated that any sorting process involves two issues - sensing and gripping. Sensing consists of detecting and classifying the items, whereas gripping involves realizing the required separation in the most efficient way. As a sorting process, sizing includes two operations: fruit size measurement/classification and its effective separation along different takeaway cross belts (receiving belts) placed below the sizer ejection points. As reviewed by Peleg (1985b), with mechanical sizers these operations co-occur in space, whereas with electronic sizers sensing and ejecting take place at different zones of the sizer. This means that electronic sizers must be equipped with devices such as shaft encoders for identifying the location of fruit at all times, as well as some means for separating ("singulating") fruits into individual "cups" or "pockets". Shawver and Henderson (1973) defined singulation as the act of organizing items in an initially disorganized state into a regular configuration, although not necessarily oriented in a particular way. They further defined three degrees of singulation. In the first, articles are received in a three-dimensional (3-D) bulk arrangement and are organized into a disordered monolayer with indeterminate and irregular spacing between articles. In the second, articles are received in a disordered monolayer and are organized into a row (or rows) with indeterminate and irregular spacing between articles within a row. Finally, in the third, articles are received in a row and are organized into a specified configuration with definite, predictable spacing between articles. Most commercial electronic sizers now use the third type of singulation.

Although electronic sizers have now almost totally displaced mechanical ones, it is unclear whether they have resulted in a superior sizing accuracy. For example, Miller (1990), working on tangerines, compared the sizing accuracy of two types of mechanical sizers and an electronic sizer comprising a weight and an optical subsystem. He found that one of the mechanical sizers, a diverging grommet roller sizer, had the worst accuracy for all four sizing units, whereas the other mechanical sizer, a belt and roller unit, showed no significant differences compared with the electronic sizer. Likewise, it is unclear whether electronic sizers have resulted in a significant reduction in the damage inflicted to the produce. Thus, Miller (1990), found no significant difference in damage level with the three types of sizer (diverging grommet roller, belt and roller, and electronic weight-optical). Damage assessment was based on weight loss, decay level, and a dye test as indicators of recent injuries. García-Ramos et al. (2004), using an instrumented sphere, assessed the mechanical aggressiveness of four different sizers commonly used in stone-fruit packing lines, three were electronic and the fourth was mechanical. By measuring the impacts registered in the transfer points, they found no differences among the different sizers. They concluded that any sizer could perform correctly with a correct design of the transfer points.

Therefore, it has not been proven that electronic sizers have better performance compared with mechanical sizers, in terms of sizing accuracy and damaged to the produce. Some practical aspects can be considered that may account for the obsolescence of mechanical sizers. First, electronic sizers provide a direct interface for PLU (Price-Look-up) labeling and packing-line flexibility on diverting fruit to final packing stations (Miller and Drouillard, 2001). Second, electronic sizers compute the amount of fruit ejected at each ejection point, thereby supplying real-time throughput data to the packing-house computer management system (Torregrosa and Orti, 1999). Third, many electronic sizers incorporate video cameras, that allow for color sorting and, in some cases, blemish sorting; this is, in part, due to the third-degree singulation used in these machines. This type of singulation also allows the on-line set-up of devices such as firmness sensors and spectrophotometers for measuring produce IQ. Considering external quality only, in a modern fruit packing line it is typical to find one of the following: vision-based sorters, electronic weight-based sorters, or integrated sorters including vision and weight modules.

Produce can be sized according to different physical parameters, such as diameter, length, weight, volume, circumference, projected area, or any combination of these (Peleg, 1985a). Hence, sizing methods can be classified into two categories, weight and dimensional, the latter referring to volume, axes, projected area and perimeter measurements. For many produce, the European Communities (EC) marketing standards for fresh fruits and vegetables have ruled that the size is determined "by the maximum diameter of the equatorial section", whereas in other cases it is determined by the fruit weight. Similarly, in the United States, standards for grades of several produce are defined by fruit diameter, "the greatest dimension measured at right angles to a line from stem to blossom end". However, the fact that size groups must be classified according to a given parameter does not compel the packer to perform the sizing operation using a machine which specifically measures this parameter. For example, in the case of oranges, where size is determined according to maximum diameter of the equatorial section (EC Commission Regulation, 2001), if there is a high correlation between this diameter and the fruit weight, the packer will probably be able to use a weight sizer rather than a dimensional sizer. Of course, the size information appearing in the package label must be expressed in terms of the parameter stipulated by the appropriate marketing standard.

\section{Fruit weight direct determination}

Although most of this review focuses on dimensional sizing, it is useful to include some background information on weight sizing. Weight sizing can be accomplished by direct or indirect methods. The indirect method involves estimating fruit weight from 
dimensional measurements such as projected area using a model or equation (Jahns et al., 2001; Varghese et al., 1991; Jarimopas et al., 1991; Davenel et al., 1988).

Fruit weight direct determination can be performed using a mechanical or an electronic weight sizer. The main design difference between both concepts is that the mechanical sizer weight measurements are performed at the ejection points; each mechanical sizer ejection point represents a weight measurement point, whereas electronic weight sizers have a single weight measurement point per lane, typically arranged a short distance before the first ejection point. The advantages of electronic weight sizers over mechanical sizers, according to Studman (1999) are: it is easier to recalibrate the machine for different size groups because it is not necessary to adjust all the ejection points individually; the electronic weight grader can achieve a more accurate weight measurement; and higher operating speeds are possible. Francés et al. (2000), using an electronic weight sizer, processed a 150-g weight pattern piece 100 times at a speed of 16 fruits per second, obtaining a coefficient of variation (CV) of $0.34 \%$. Disadvantages of the electronic weight sizer, according to Studman (1999), include the cost of the equipment and the need of personnel trained in electronics and computing. After considering the advantages and disadvantages, we conclude that electronic weight sizers have now superseded and replaced mechanical sizers.

\section{Reference method for estimating the volume of fruits and vegetables}

Obtaining fast and accurate weight measurement of a body in the laboratory is straightforward by using a precision top-loading balance. However, obtaining fast and accurate volumetric measurements is more troublesome. The method of specific gravity bottle, or of pycnometer and toluene, which owing to its high precision is considered the benchmark for volume determination of seeds and grains, is considered too slow. For larger commodities such as an apple, faster methods may have merit, even at the expense of accuracy. The rationale for this is that for the same relative error, a greater error (numerator in Eq. (7), see Appendix) is allowed when measuring the volume of an apple compared with, for example, a corn kernel.

For medium-sized fruits (such as apples, oranges, peaches), the xylometric method is an obvious alternative. This method involves measuring the volume of an object by submerging it in a beaker of water and measuring the displacement of the water in the beaker graduations. As water is uncompressible, and provided the volume of water absorbed by the fruit is small, the change in water height should yield a good approximation of the fruit volume. Nevertheless, this method is associated with two sources of error. The main is due to the ratio of the water free surface area $(A)$ to volume $(\mathrm{V})$, which is high for a beaker compared with a graduated cylinder. To achieve accurate fruit volume measurements, a high $\mathrm{A} / \mathrm{V}$ is a disadvantage, but if the volume of medium-sized fruits is to be measured, a vessel similar to a beaker is required so that the fruit can fit into it. The second source of error is because the operator eye level is at the water free surface to achieve an accurate reading.

Theoretically, a good alternative to the xylometric method is use of an "eureka can". This instrument, which is essentially a beaker with a spillway spout, is filled with water until it overflows. The object, the volume of which is to be measured, is then submerged in the eureka can and the water that is displaced via the spout is collected in a graduated cylinder, and the volume of the object can be accurately calculated. However, in practice, the eureka can requires a long measurement period to achieve an accurate measurement; for example, Forbes (2000) noted that the water continued to drip out of the eureka can spout for several minutes after the fruit had been submerged.
Therefore, we can conclude that the best method for measuring the volume of most fruits is by water displacement based on the Archimedes principle. A methodology based on this principle was outlined by Mohsenin (1970). This method represents a good balance between accuracy and measurement speed. Another possibility could be the design of an ad hoc pycnometer, as outlined by Forbes (2000).

In situations where fruit growth is continuing, it is preferable to estimate fruit volume by air displacement using an air pycnometer. This is because submerging fruits in water can make them more susceptible to subsequent fungal attack. Air pycnometers are based on the ideal gas (Boyle-Mariotte) law. The main disadvantage of these instruments is the long measuring time. Iraguen et al. (2006) designed a portable air pycnometer to measure the volumes of grape clusters attached to vine plants. Using a multivariate linear regression calibration technique instead of the analytical ideal gas law approach, and with the reference volumes being obtained from water displacement approaches, their device yielded a RMSE of $19.3 \mathrm{ml}$ and a RMSPE of $3.8 \%$. The complete measurement cycle for one cluster took about $45 \mathrm{~s}$.

\section{Electronic systems to determine horticultural produce dimensional size}

Over the past few decades, different electronic systems have been developed for non-destructive determination of horticultural produce dimensional size. We propose a classification of these systems into six different groups, according to their principle of measurement.

- Systems based on measurement of the volume of the gap between the fruit and the outer casing of embracing gauge equipment.

- Systems that calculate fruit size by measuring the distance between a radiation source and the fruit contour, where this distance is computed from the time of flight (TOF) of the propagated waves.

- Systems that rely on the obstruction of light barriers or blockade of light.

- Two-dimensional (2-D) machine vision systems.

- Three-dimensional (3-D) machine vision systems.

- Other systems. This group includes systems based on internal images, such as computed tomography (CT) or magnetic resonance imaging (MRI), as well as some other approaches not included in the other groups.

Some of the measurement systems referred to in this paper could be assigned to more than one of the above-listed groups; for example, the optical ring sensor system (Gall, 1997), described in the next subsection, which could be assigned to the first and third groups.

6.1. Systems based on measuring the volume of the gap between the fruit and an outer casing

The three systems in this group involve a surrounding casing through which the fruit is passed. Although not being machine-vision-based, these are 3-D systems. In each case, the surrounding or outer casing is of fixed dimensions, whereas the fruit size (the characteristic being measured) is variable. Although the principle of measurement is different for each system, all systems share the idea of measuring the volume of the gap between the fruit and the outer casing.

One of these systems is the optical ring sensor system developed by Gall (1997). This light-blocking-based system consists of a circular frame on which a large number of infrared transmit- 
ters and receivers are alternately arranged (Fig. 1). When the inner space of the ring is clear, every receiver detects the light emitted by the activated transmitter owing to the Lambertian response of all the transducers. However, as soon as an object is introduced in the ring, a shadow zone appears, corresponding to the receivers obscured from the activated transmitter. The transmitters are switched on in sequence round the ring, with the emitted light rays representing chords in the circumference. The two closest non-interrupted chords, or 'tangential' chords, are used to approximate the object's contour. The algorithms are the same for 2-D and 3-D objects. Fruit cross-sectional area (Fig. 1) is computed as the difference between the area of the whole circle encompassed by the ring and the sum of the triangles and segments of the circle that comprise the gap between the object's contour and the ring (Eq. (1)).

$A_{\mathrm{f}}=\pi r^{2}-\sum\left(A_{\mathrm{T}}+A_{\mathrm{C}}\right)$

where $A_{\mathrm{f}}$ is the area of the fruit cross-section, $r$ is the ring radius, $A_{\mathrm{T}}$ is the area of a triangle, and $A_{C}$ is the area of a circle segment.

The optical ring sensor system can be used to estimate the volume of fruits travelling at high speed, up to $2 \mathrm{~m} / \mathrm{s}$ when measuring elongated produce such as cucumber or zucchini (Moreda, 2004). The system generates an enveloping helix used to estimate the fruit's length, volume and major and minor axes of two particular cross sections. Owing to the small pitch of the helix, its turns are approximated to cross-sections. Fruit volume is calculated by summing the individual products of the cross-section areas multiplied by the helix pitch. Gall et al. (1998), studying potatoes, reported CVs of less than $2.5 \%$ for tubers larger than $100 \mathrm{ml}$. Owing to the geometry of the system, errors were larger for smaller objects. Moreda et al. (2005) determined optimal levels of speed and passage zone for an on-line size determination system comprising an optical ring sensor and a singulator made of two angled belts. In a subsequent work, Moreda et al. (2007), working on tomato and kiwifruit, analyzed the effect of fruit orientation on the precision of measurements obtained using the optical ring sensor. Controlled vs random orientations were compared. Controlled orientation implied an absence of fruit swinging movement (stabil-

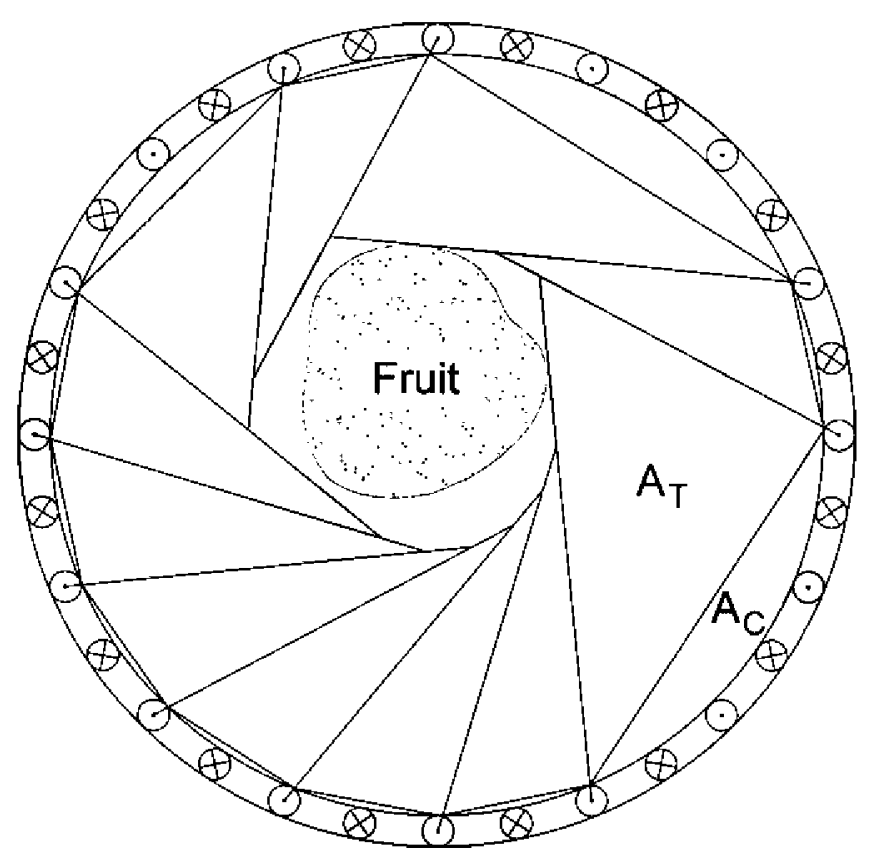

Fig. 1. Triangles and circle segments making up the area between the fruit contour and the optical ring sensor frame (redrawn from Gall et al., 1998). ity). Random orientation negatively affected the precision of volume measurements owing to the swinging movement of the fruit when crossing the optical ring sensor. The conclusion was that the sizing provisions of the European Communities marketing standard for kiwifruit were met by sensor measurements of volume in the controlled orientation (RMSE $=6.9 \mathrm{ml}$; RMSPE $=5.6 \%$ ), but not in the random orientation. On the other hand, Moreda (2004) obtained a RMSE of $26 \mathrm{ml}$ (RMSPE $=5.8 \%$ ) for volume estimates of zucchini.

Kato (1997), working on watermelon, devised an electric method for measuring fruit volume based on the fundamental relationship between the capacitance of concentric double spheres and the radius of the inner sphere. In its practical application, a precision instrument measured the capacitance between the inner sphere, generated by the watermelon, and the outer sphere or external electrode, represented by a polygonal grounded tunnel (Fig. 2). The internal electrode consisted of conductive rubber suckers on which the watermelon was placed. Watermelon volume was measured as the fruit passed through the tunnel at a speed of $0.22 \mathrm{~m} / \mathrm{s}$, which corresponded to a throughput of 0.4 fruits/s. This method yielded an RMSE of $26 \mathrm{ml}$, and an RMSPE of $0.4 \%$, both of which rather small, but it had the disadvantage of requiring correctly oriented watermelons. In Kato's method, the polygonal tunnel was the outer casing, whereas the fruit volume was estimated from the electrical capacitance of the gap.

Nishizu et al. (2001) developed an on-line volume measurement system based on the relationship between the volume of an object in a Helmholtz resonator and an acoustic resonant frequency. A Helmholtz resonator consists of a narrow part or 'throat' and a wide part called the chamber or cavity, and the two parts together resemble a wine bottle. Blowing or hitting the lip of the throat creates a sound that includes a resonant component. This component is called the Helmholtz resonant frequency, and it depends on the cavity volume minus its content. The practical effect is that the resonant frequency provides information on the content volume. In the concept by Nishizu et al. (2001) the resonator cavity wall featured two lateral openings, through which a conveyor belt passed (Fig. 3). A "chirp wave" sound was transmitted into the cavity and a microphone was used to detect the response signal, from which the resonant frequency was extracted. The researchers tested their system on

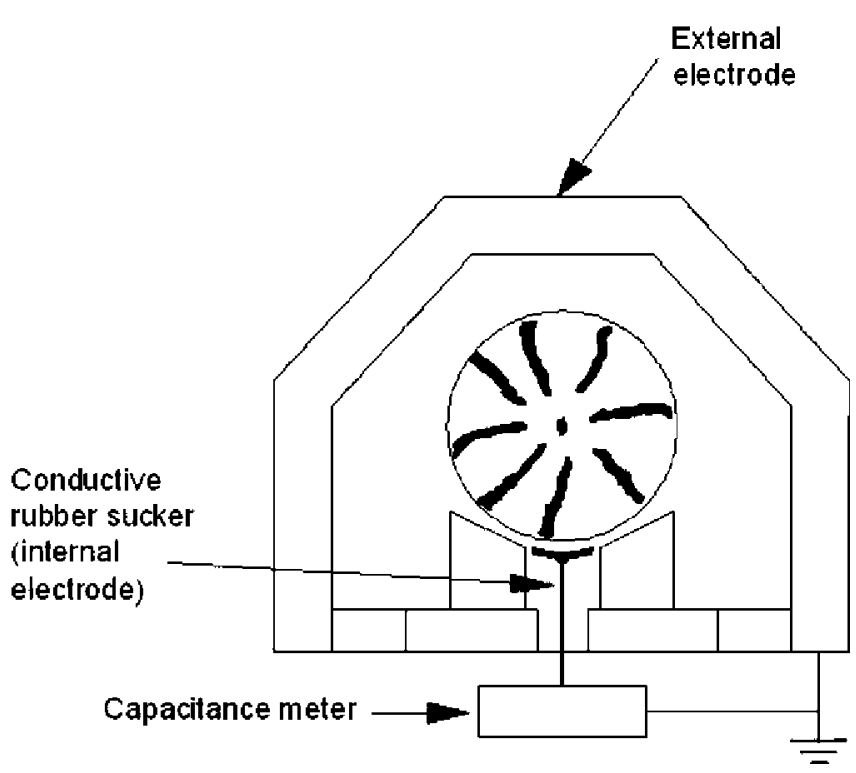

Fig. 2. Setup of the on-line electrical capacitance system for watermelon volume measurement (redrawn from Kato, 1997). 


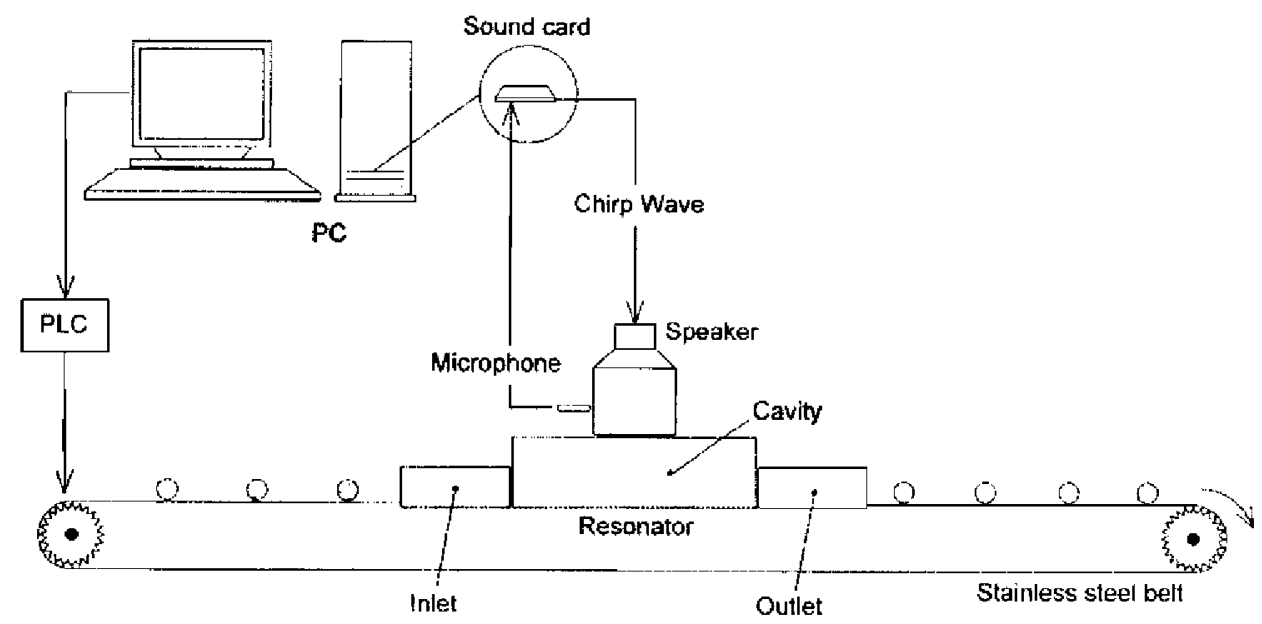

Fig. 3. Setup of the on-line Helmholtz resonator system for food volume measurement (redrawn from Nishizu et al., 2001).

wooden blocks, metallic blocks, and boiled rice. The system delivered a high correlation $\left(r^{2}=0.97\right)$ with the actual volume, although the operating speed was rather slow (maximum $0.05 \mathrm{~m} / \mathrm{s}$ ). As the speed increased, the prediction accuracy decreased. This was due to movement of the object out of the center of the resonator during the duration of the sound chirp. They did not assess the precision of the system. In this model, the resonator cavity was the outer casing, whereas the gap volume was measured as a function of the resonant acoustic frequency.

\subsubsection{Discussion}

of the three systems described above (optical ring sensor, electrical capacitance, and Helmholtz resonator), the most versatile is the optical ring sensor because it can measure fruit axes in addition to volume. In terms of the precision of the volume estimates, only the ring sensor and the electrical capacitance method are similar; no RMSE value is available for the Helmholtz resonator system. The electrical capacitance method, with a RMSPE of $0.4 \%$, is more accurate than the optical ring sensor (RMSPE 5.7\%). In terms of system throughput, the optical ring sensor (standard conveying speed of $100 \mathrm{~cm} / \mathrm{s}$, up to $200 \mathrm{~cm} / \mathrm{s}$ for some elongated produce) is superior to the other two systems. The Helmholtz resonator system (conveying speed $5 \mathrm{~cm} / \mathrm{s}$ ) is the slowest system, whereas the electrical capacitance system, with a conveying speed of approximately $25 \mathrm{~cm} / \mathrm{s}$, is intermediate. The throughput limitation of the Helmholtz resonator system leads us to conclude that it does not yet seem ready for widespread commercial use; therefore, the following comparisons have been limited to the other two systems. If we do not consider that the electrical capacitance system has only been tested on watermelons and we suppose that a smaller machine is developed for medium-sized fruits, and equivalently, that a larger optical ring sensor is designed with a diameter sufficiently large for a watermelon to pass through, then we can compare the two systems. The electrical capacitance method is more accurate than the optical ring sensor, although it has a lower throughput, approximately one quarter that of the ring sensor. On the other hand, the electrical capacitance machine requires oriented fruits, whereas the optical ring sensor only requires this for axis measurements. However, zucchini are an exception to this: owing to their length, correct orientation is required even when measuring volume to ensure they can cross the optical ring sensor. However, this does not normally cause a problem because it is quite easy to mechanically achieve the required orientation for zucchini using angled belts. Finally, to obtain accurate volume measurements, the optical ring sensor needs fruits with no swinging movement when crossing the ring.

\subsection{Time of flight (TOF) range finding systems}

A basic consideration regarding this group of systems is that whatever the type of waves involved, mechanical or electromagnetic, in addition to a transmitter to generate the signal and a receiver to detect the reflected signal, an accurate measurement of time (especially with electromagnetic waves) is also needed. Laing et al. (1995) developed an apparatus for rapid estimation of fruit size in the field, which consisted of three rods forming an inverted tripod (Fig. 4). Unlike a conventional photography tripod, this one was fixed - the angle formed by the three rods was constant. However, an inverted tripod instead of a solid truncated cone was used because the device was intended for measuring the size of fruits attached to branches of trees; thereby gaps in the recipient wall were necessary to allow the branches to pass through. An ultrasonic distance sensor was arranged on the base of the tripod (Fig. 4). When a fruit was placed inside the inverted tripod, it would slide down until it became stuck. The point at which it stuck depended on the size of the fruit. Large fruits would stick far from the ultrasonic sensor, whereas small fruits would slip down and become stuck near the ultrasonic distance sensor. The authors measured a set of lemons with this device and with a vernier caliper, obtaining a RMSE of $1.1 \mathrm{~mm}$ and a RMSPE of $2.0 \%$. The measurement of one fruit took $10 \mathrm{~s}$.

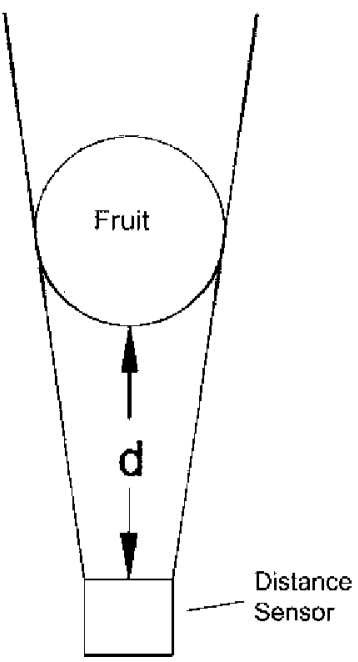

Fig. 4. Schematic of the inverted tripod system for fruit size determination based on TOF of ultrasonic waves (redrawn from Laing et al., 1995). 
Ultrasonic distance sensors have been used for sizing fruits in packing lines. For instance, Miller (1993) compared a video-camera sensor with an ultrasonic sensor, both of which were operating at a translation speed of $5 \mathrm{cups} / \mathrm{s}$-lane. The ultrasonic system delivered only one average diameter for each fruit. Both sensors showed high dimensional accuracy when tested with a set of artificial grapefruit, compared with manual caliper measurements of fruit equatorial diameters (relative error of $1.7 \%$ for the camera system and $1.8 \%$ for the ultrasound system). The repeatability of both systems was also high (CVs of $0.46 \%$ and $0.48 \%$ for the camera and ultrasound system, respectively). The artificial grapefruits used were all of the typical desired shape. On the other hand, in a misshapen grapefruit, the magnitude of the polar and the equatorial diameter are inverted compared with a well-shaped grapefruit. A suitable way of detecting misshapen fruits is by identifying the polar or stem-calyx axis. By doing so, uncertainty regarding whether the diameter measured is an actual equatorial diameter of a wellshaped grapefruit or is the polar diameter of a misshapen fruit can be resolved. As neither the ultrasonic system nor the camera system analyzed in Miller (1993) had the ability to identify the stem-calyx axis, if a natural batch of grapefruits had been measured, the precision of both techniques would had been lower, owing to the probability of occurrence of misshapen fruits.

Another technique that could eventually be used to determine fruit size is time of flight (TOF) laser range finding. There are two different techniques used in laser range finders, which are commonly known as laser scanners: TOF and triangulation. The latter, considered one of the most accurate methods for reconstructing the 3-D surface of an object, is discussed in Section 6.5. A TOF laser range finder measures the distance from the scanner to a surface by timing the round-trip time of a pulse of light. Compared with triangulation laser range finders, TOF laser range finders are better suited to measurements with a large depth of field, even in the order of kilometers, therefore they are not usually used for industrial inspection. Their accuracy is about $10^{-4} \mathrm{~m}$, whereas triangulation laser range finders have an accuracy of $10^{-6} \mathrm{~m}$ (Besl, 1989).

\subsection{Systems based on the blocking of light}

Iwamoto and Chuma (1981) described three opto-electronic systems based on the blocking of light. The first (I in Fig. 5) measures the horizontal width of fruits in the direction of movement.
It is comprised of a couple of transmitter and a receiver, placed at opposite sides of the conveyor. Provided the space between the transmitter and the receiver is clear, the receiver will detect the light emitted by the transmitter. When a fruit passes through the system, the light path is blocked. For a given conveyor speed, fruit size is correlated with the duration of the light blocking. The second type (II in Fig. 5) also measures the horizontal width of fruits in the direction of movement. It consists of several transmitters with their corresponding receivers placed at opposite sides of the conveyor. Both types of transducers are arranged in pairs. The distance between the elements of each pair, or "within-pair" distance is decreased in the forward direction. Distances are determined according to commercial size ranges for the produce in question. When a fruit traveling on the conveyor reaches a pair at which both beams are simultaneously blocked, the fruit is assigned to the size group matching that within-pair distance. The third type (III in Fig. 5) measures the vertical width or height of a fruit as it passes between two lateral vertical arrays of optical transducers, one of which is equipped with LEDs and the other with photodiodes. The ideal scenario for the third type of system would be for each receiver to detect only the light that is projected by the transmitter located at the same height; however, when LED transmitters are used, a small light diffusion occurs, so the adjacent receivers also detect light. An economic way of solving this problem is by logical comparison (Fon et al.,1990); an alternative but more expensive solution would be the use of laser light.

When classifying satsuma tangerines into six size groups, Iwamoto and Chuma (1981) reported average sorting accuracies of $92.8 \%$ for the first type of sizer, and $93.9 \%$ for the second type. They did not report on the throughput of these sizers. Chen et al. (1992), classifying lemons into three size groups using a sizer of the third type, obtained a sorting accuracy of $94.7 \%$. The throughput of this sizer was of 0.8 fruits/s-lane.

Hahn (2002) developed a sizer for jalapeño chillies based on the blocking of a plane or sheet of laser light. Fruits traveling on a conveyor belt were passed between a laser line generator and a bar of photodetectors, both of which were arranged vertically. The belt ran at a speed of $1 \mathrm{~m} / \mathrm{s}$, allowing sorting up to 15 fruits/s.lane. To obtain accurate measurements, fruits had to be oriented on the conveyor belt with their polar axes perpendicular to the line. The photodetector bar scanned the laser stripe every $20 \mathrm{~ms}$. Each scan showed a different number of photodetectors that did not receive
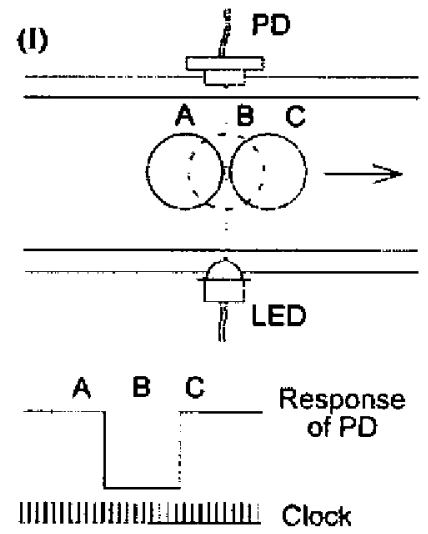

PD: Photodiode LED: Light emitting diode
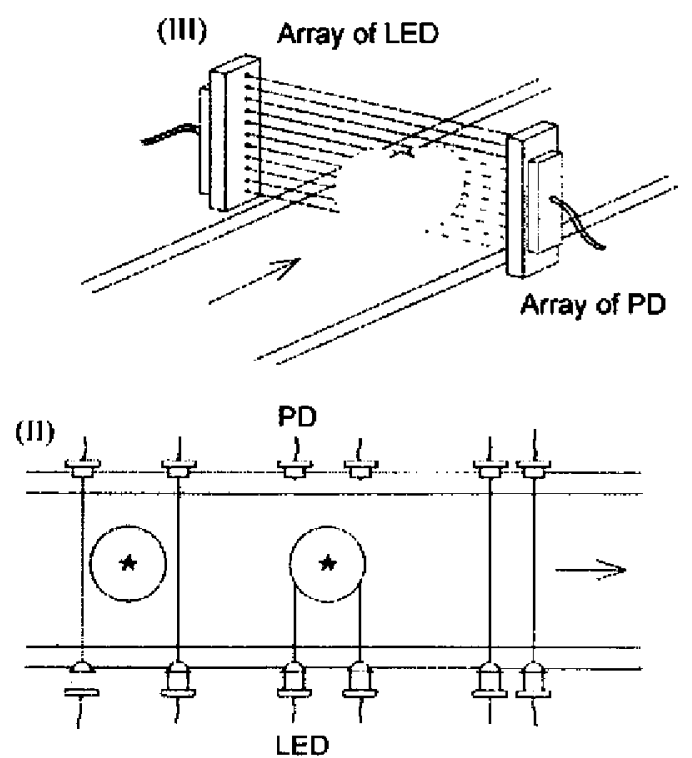

Fig. 5. Three types of optoelectronic sizing systems based on the obstruction of light barriers (redrawn from Iwamoto and Chuma, 1981). 
the laser stripe; this quantity was recorded in the memory of a microcontroller. For each chilli, the maximum value saved in the microcontroller memory corresponded to the fruit height or vertical width. Horizontal width measurements were obtained after counting the number of blocked laser stripes as the fruit advanced on the conveyor belt. For each chilli, the minimum horizontal or vertical width gave the final width used for classification in three size classes. The second class included those fruits ranging from 24-29 $\mathrm{mm}$ in width, whereas the first and third classes included fruits greater than $29 \mathrm{~mm}$ or smaller than $24 \mathrm{~mm}$, respectively. For the first class (large) chillies, the sorting accuracy was $92 \%$ when the chillies were manually oriented and $87 \%$ when the system operated in the fully automatic mode. Hahn (2002) proposed the use of machine vision to increase sorting accuracy. Two cameras should be used to view the top and lateral chilli sides and detect chilli horizontal and vertical widths, respectively.

\subsubsection{Discussion}

Both type I and II (Fig. 5) sizers measure fruit horizontal width, whereas type III sizers measure the vertical width or height. Therefore, for oblate fruits such as conventional ('beefsteak') tomatoes, tangerines and grapefruits, which have a clear resting or stability position when tossed on a horizontal surface, types I and II would be better because according to most marketing standards the size is determined by the equatorial diameter. Nevertheless, type III has the important advantage that, in addition to linear dimensions (diameters), it can also measure projected area by integrating the different heights measured as the fruit passes. On the other hand, for prolate fruits such as lemons, the type III sizers are better, because, owing to the stability position, the height measured by the sizer corresponds to the equatorial diameter. For sizing of lemon with types I and II sizers, an orienting device should be installed to orient the polar axes perpendicular to the line; otherwise the polar diameter could be mistaken for the equatorial diameter. Sorting accuracies are similar for the three types. No data are available on the throughput of types I and II sizers, whereas the throughput of a type III sizer when measuring lemons was 0.8 fruits/s.lane. Due to the lack of information on the throughput of systems I and II, only the type III (Chen et al., 1992) can be compared with the system of Hahn (2002). The throughput of the system of Hahn (2002) is much higher than that of Chen et al. (1992) (15 fruits/s.lane vs 0.8 fruits/s.lane, respectively), although the sorting accuracy is lower ( $87 \%$ vs $94.7 \%$, both values corresponding to classification into three size groups). The design of both systems is similar, with the main difference being that the machine of Chen et al. (1992) is cheaper because it does not use laser light.

\subsection{Two-dimensional machine vision systems}

These systems use video-cameras, usually equipped with CCD or CMOS sensors, to take brightness images of the fruits. Specially developed computing hardware and software are used to analyze these images with the aim of estimating features such as diameter, perimeter, or projected area from the fruit 2-D digital profile image. Apart from the camera itself, the main hardware components are the lighting devices, the image capture board, and the computer hardware. The image capture board, or digitizer, converts pictorial images into numerical form (Brosnan and Sun, 2004). The system software performs image preprocessing, segmentation, and feature extraction or measurement. Today, most packing houses incorporate 2-D computer vision technology in their optical sorters. In a typical system, fruits traveling on a chain conveyor are viewed from above by one or more zenithal cameras. Sometimes lateral mirrors are also installed to increase the number of views. Miller (1987) has reported that, for analyzing fruit size and shape by machine vision, backlighting can be used; however, front light- ing is usually preferred because it is easier to implement and supplies the necessary reflectance data for color and blemish grading.

Wechsler (1981), using the chain-code technique for characterization of digital image boundary, reported that area measurements are more reliable than perimeter measurements because the quantization errors introduced by the digitization and thresholding processes tend to have no effect on the final measurements. Sarkar and Wolfe (1985), working on fresh market tomatoes, developed image analysis algorithms for classification based on fruit size, shape, color and surface defects. For shape and size assessment they used the chain-coded boundary of the tomato profile image. Despite being aware of the recommendations by Wechsler (1981), they selected perimeter as the size measurement because, in preliminary analyses of tomato profiles, they had found that perimeter and area correlated equally well with the mean equatorial diameter, and that perimeter measurements were computationally less expensive than area measurements. In the application of their system to classification of tomatoes in three size groups (small, 61-70 mm; medium, 70-80 $\mathrm{mm}$; and large, greater than $80 \mathrm{~mm}$ ), they obtained an overall error rate of $5.6 \%$. Most of the misclassified tomatoes were of the medium size group and all had diameters that were borderline between classes.

Bato et al. (2000) used the projected area of the fruit image as the parameter for classifying strawberries into three size groups, regardless of the fruit orientation angle. The class limits of the three size groups were established by measuring the areas of 50 strawberries which had been pre-sorted in a commercial packing house. Using these judging criteria as a standard, they obtained a sizing accuracy (classification success rate) of $98.6 \%$ with 200 strawberries of different shapes and sizes. They concluded that the total number of pixels resulting from the scanning procedure had to be multiplied by the corresponding pixel size of the specific camera height to determine the actual strawberry projected area for size classification according to the developed standard.

The typical axes used for fruit size and simple shape determination are the equatorial or transversal diameter, and the polar diameter or length. The reference method for measuring these diameters on small- and medium-sized fruits involves a vernier caliper. Owing to the odd shapes of horticultural produce, shape and dimension or size are 3-D values; that is, the same measurement on the same fruit often varies in different planes around the central axis of measurements (Affeldt et al., 1994). This means that there are several possible equatorial and polar diameters in a same piece of fruit.

Miller (1990), working on tangerines, used an algorithm to calculate the position of the fruit image centroid. Eight axes were scanned with center on the centroid at incremental angles of $22.5^{\circ}$. The length of each axis was computed, and the eight axes were ranked from minimum to maximum. Miller took the mean of three of the greater axes, in particular the fifth, sixth and seventh, as the equatorial diameter. This method had the disadvantage of being dependent on fruit orientation.

Aleixos (1999) and Aleixos et al. (2002), working with machine vision on citrus fruits, defined the boundary of the fruit image and calculated the centroid coordinates. They then computed the distance from each boundary pixel to the centroid. The major axis was located in the direction of the maximum distance, whereas the minor axis was determined as perpendicular to the major axis and passing through the centroid. Their algorithm, which had the advantage of being independent of fruit orientation, was applied to seven consecutive infrared images of each fruit, each of which was obtained while the fruits were transported below the camera on a bicone conveyor chain at a speed of 10 fruits/s. For computing the size of tangerines, the reference equatorial diameter was regressed against the minimum, maximum, and average of the seven major axes estimated by the vision system. Computation of lemon equatorial diameters involved the same procedure, but from the 
seven minor axes, since in a lemon the equatorial diameter is smaller than the polar diameter. The best result obtained on tangerines was a RMSE of $1.98 \mathrm{~mm}$, corresponding to the average of the major axes, whereas the best result for lemons was a RMSE of $0.99 \mathrm{~mm}$, corresponding to regression against the minimum of the minor axes. The greater accuracy in size estimation of lemons compared with tangerines was due to the elongated shape of the lemons, resulting in rotation around a single axis; by contrast, tangerines do not always rotate around the same axis, which led to an increase in measurement variability.

Blasco et al. (2003) developed an on-line machine vision system, which obtained four images per fruit for automatic quality grading of apples, peaches and oranges. As the apples were not oriented, they calculated the equatorial diameter, defined in the image as the length of the principal axis of inertia, from the view in which the stem was located nearest the fruit centroid. For evaluating the sizing performance of their system, they conducted a repeatability test using a large number of apples. The test consisted of passing the fruits through the machine, which boxed them into one of four size groups. The respective boxes were then passed repeatedly through the system, and the changes in the classification were observed and recorded. The repeatability varied from $89 \%$ for the fruits of the smallest size to $100 \%$ for the largest apples, with an average of $93 \%$. The results were considered good, because the vision system rate of misclassification was $7 \%$, lower than the $10 \%$ allowed by the respective marketing standard. In terms of the machine yield, the time taken by the system to inspect the fruit was less than $300 \mathrm{~ms} /$ fruit; however, the authors concluded that this could be reduced to less than $50 \mathrm{~ms}$ with faster computers and by improving the algorithms to allow overlaps between the acquisition and the image processing procedures. A conservative estimate might be $100 \mathrm{~ms}$, which corresponds to a throughput of 10 fruits/s-lane.

In some 2-D machine vision applications the features extracted from the images are used to determine fruit volume. Sabliov et al (2002), developed an image-processing-based method to measure the volume of ellipsoidal agricultural produces such as eggs, lemons, limes, and peaches. Their method modeled each object as a sum of superimposed elementary frustums of right circular cones. The dimensions of individual frustums were determined from a digitized picture of the product acquired by a CCD camera. Using their desktop vision system CVs of $2.4 \%, 3.4 \%, 5.5 \%$, and $3.6 \%$ were obtained for eggs, lemons, limes, and peaches, respectively. Marchant (1990), using dimensional analysis, stated that for a solid of fixed shape but variable size scale, any size measure including the dimension (length) ${ }^{3}$ will be proportional to volume. Based on this, and assuming a constant density for the tubers, he estimated the weight of potatoes from the average of (projected area) ${ }^{2} /$ length derived from 12 different images that were captured as the tubers rolled along a conveyor system. In Marchant's model, no attempt was made to mechanically singulate the tubers in the direction across the conveyor. The potatoes were separated in parallel rows, sitting in the troughs between adjacent rollers. As adjacent tubers in a row would usually touch, a blob-splitting algorithm was developed for single tuber identification. The RMSE of the estimated weight was $14.2 \mathrm{~g}$ (Marchant et al., 1989) for a mean tuber weight of $200 \mathrm{~g}$. Although the value of the RMSPE was not reported, a rough estimate of the RMSPE can sometimes be computed by dividing the RMSE by the mean. In this way, an approximate RMSPE of $7 \%$ is obtained. From the latter value, we can conclude that the system by Marchant would not be capable of classifying potatoes according to their starch content, because a boundary RMSPE of $1 \%$ is required for a three-way classification (Hoffmann et al., 2004). On the other hand, the foregoing numerical comparison of RMSPEs is not even necessary, because the system of Marchant assumes a constant tuber density as an initial hypothesis, hence it cannot perform density sorting.
Forbes and Tattersfield (1999b) developed a machine vision algorithm that estimated fruit volume from 2-D digital images. Their method, which included a neural network, was rotationally invariant and did not rely on conveyor mechanisms for aligning the fruits. Working on pears, they reported a RMSPE of $3 \%$ when a single image was analyzed, and $1.9 \%$ when the volume was estimated from a set of four images. Forbes (2000) reported RMSPEs of $1.6 \%, 1.3 \%$, and $5.3 \%$ for lemons, oranges and potatoes respectively, when the volume was estimated from a set of four images.

\subsubsection{Discussion}

According to Imou et al. (2006), the system by Bato et al. (2000) was associated with some technical or cost problems, and so it has not been widely used. For valid comparisons with systems of other groups, in this section we only discuss 2-D machine vision systems for which some measure of precision is available. Therefore, the studies that report only on sorting accuracy (Bato et al., 2000; Sarkar and Wolfe, 1985) or sorting repeatability (Blasco et al., 2003) are excluded from further comparison here. Also, desktop systems such as that developed by Sabliov et al. (2002) are not included in the comparison. This limits the comparison to the systems by Aleixos et al. (2002), Forbes (2000), and Marchant (1990). A serious limitation to any comparison between the Aleixos system and the other two systems (Forbes, Marchant) is that Aleixos did not report a RMSPE value or the mean actual equatorial diameter of lemons or tangerines (with the mean actual equatorial diameter, an estimate of RMSPE might be calculated, using the RMSEs reported in Aleixos (1999) and Aleixos et al. (2002)). Since Aleixos only measured diameter and the other two authors only measured volume, comparisons attending to RMSEs are not possible. Hence, the only valid comparison is between the systems by Forbes and Marchant, because both authors reported on fruit/tuber volume. Although both systems are 2-D machine vision systems, their design is very different. One of the main differences is that Marchant concept uses a roller conveyor without singulation across the line instead of independent lanes. The system by Marchant, which has the benefit of a very high throughput (up to 40 tubers/s), yielded a RMSPE (7\%) that was higher than the system developed by Forbes (5.3\% for potatoes). The Marchant system is apparently cheaper than the Forbes system because it only uses one camera, whereas the Forbes system uses four cameras. Besides, the roller conveyor used by Marchant is presumably more cost-effective than the bicone conveyor that the system of Forbes would require. The Marchant system has the advantage that it has been tested on-line, whereas the Forbes system was tested in a desktop assembly mode, with a camera and three mirrors; however, the work of Forbes aimed to provide compatibility between his method and commercial machine vision systems. Although the methods of Forbes are intended for use in conjunction with color and blemish algorithms of existing commercial machine vision systems, the concept of Marchant, despite having the advantages of low-cost and huge throughput, cannot perform color or blemish sorting.

\subsection{Three-dimensional machine vision systems}

This group of systems includes a vast number of techniques, which in the future will probably supplement 2-D machine vision based systems in many applications because automatic inspection processes increasingly require 3-D information to improve characterization of the geometry of inspected products (Poussart and Laurendeau, 1989; Hall-Holt and Rusinkiewicz, 2001; Jain, 2003; Hardin, 2006). Chen et al. (1989) stated that the capability of 2-D visual systems may be limited by insufficient information contained in the images. The most obvious limitation of 2-D images is the lack of information about height or depth dimensions and relationships among these dimensions, which, apart from fruit 
shape and surface texture recovery, have an important role in accurate volume and surface area estimation. Thus, Miller et al. (1988), working on citrus fruits, identified two factors responsible for volumetric inaccuracy, one of which was the extension of 2-D measurements for volume estimation. Lee et al. (2001) found that, with the aid of the third dimension, the measurement error in volume estimates of oyster pieces was reduced by $41 \%$ compared with the conventional 2-D area projection method.

Obtaining 3-D surface measurements is equivalent to measuring scene depth. Depth measuring results in a special type of digital image, known as range images. Besl (1989) defined a range image as a large collection of distance measurements from a known reference coordinate system to surface points on object(s) in a scene. Hence, each pixel of a range image $e^{2}$ expresses the distance between a known reference frame and a visible point in the scene.

We can classify 3-D machine vision techniques into two groups, passive and active. Besides, there is a singular approach called artificial or numerical retina, which uses a different technology to other 3-D machine vision systems.

Passive 3-D machine vision methods are known in the literature as shape or range from $X$ techniques, where $X$ represents different 3 -D cues such as stereo, shading, silhouettes or occluding contours, motion, contour or shape, shadows or darkness, texture, and fractal geometry. These 3-D cues can be determined from one or more 2-D images. All these methods try to estimate the shape of a surface, namely its orientation at each point, using any of the cues listed. To clarify the relationship between depth or range on one side, and surface orientation on the other, it is sufficient to say that surface orientation can be obtained from the range by taking derivatives. With the exception of stereovision, shape from $X$ methods cannot be used to directly calculate absolute depth, only relative depths. On the other hand, shape from $X$ methods usually require assumptions of certain regularities (Aggarwal and Chien, 1989). This is why they are generally considered as ill-posed problems.

With the important exceptions of stereovision and shape from silhouettes, most of the passive 3-D techniques are monocular systems, that is, they only require a view of the inspected object from one direction. Aloimonos (1988) reviewed almost all shape from $X$ methods, with the exception of shape from shadows. A survey of the latter was the focus of a paper by Yang (1996). In the present review, we describe only those shape from $X$ techniques that have been used in fruit and vegetable size determination. These techniques are stereovision and shape from silhouettes, the latter is also known as the volume intersection (VI) method.

The second large group of 3-D machine vision techniques includes the active methods. The name "active" is because energy is projected onto the surface of the inspected object, unlike the passive methods in which only a general illumination of the scene is required. Strat and Oliveira (2003) stated that, compared with passive techniques, easier shape extraction results are usually obtained with active optical range imaging systems. There are several comprehensive reviews on active 3-D systems; for example, Blais (2004), Battle et al. (1998), and Besl (1989). Although the group of active methods includes a range of techniques, namely triangulation, moiré interferometry, holographic interferometry, focusing, and Fresnel diffraction, in this paper we focus on triangulation, because it is the most commonly used. In fact, commercial 3-D cameras based on active triangulation are currently available (for example, from ${ }^{3}$ SICK IVP AB). Triangulation systems can be sequential, as in point scanners, or parallel,

\footnotetext{
${ }^{2}$ Range images are known by a variety of names depending on context: range map, depth map, depth image, range picture, rangepic, 2.5-D image, surface profiles, pseudo-3D, etc.

${ }^{3}$ Trade and company names are included for benefit of the reader and imply no endorsement or preferential treatment of the product by the authors.
}

as in the color-encoded stripe scheme. Despite the inherent slowness of point and single stripe laser scanners, they offer the benefit of being robust, whereas faster systems such as the color encoded stripe scheme are more prone to error. Compared with other active optical systems, the accuracy provided by the focusing technique, although limited $\left(10^{-3} \mathrm{~m}\right.$ according to Besl, 1989), would be sufficient for produce sizing. By contrast, holographic interferometry allows for very high accuracy ${ }^{4}\left(10^{-10} \mathrm{~m}\right)$; this level of accuracy is unnecessary for produce sizing requirements, and the cost of holographic equipment for this purpose alone cannot therefore be justified.

\subsubsection{Passive 3-D machine vision techniques}

Using triangulation, stereovision can derive 3-D information from images taken from two different viewpoints. The separation of the two viewpoints represents a balance between the requirement for precision in the depth estimates and the requirement that the two images are sufficiently similar to enable corresponding points on the object to be identified in both images. Therefore, the difficulty in finding matching points between the stereopair of images is one of the main challenges for application of stereovision to biological produce inspection. Hryniewicz et al. (2005) used stereovision for the 3-D shape modeling of carrots and other horticultural produce with circular cross-sections using a desktop setup comprised of two internet-connected cameras (webcams) and a slide projector as the light source. Their fruit surface reconstruction was based on extruding a circular cross-section perpendicularly to a 3-D curve. The stereovision method calculated the centers and radii of the different circular cross-sections. In the experiments conducted on apples and tomatoes, fruit equatorial diameter was estimated with an accuracy of $5 \%$, although the authors did not specify whether this value corresponds to RMSPE or another statistical parameter. They concluded that results could be further improved by obtaining stereopair images from different stations or viewpoints. Interestingly, a set-up of the latter type was used by Wu et al. (2004) to obtain the 3-D shape of live pigs. The stereo imaging system was comprised of six cameras arranged in three stereo pods that captured the side, top, and rear views of each pig. Each stereoview was processed to produce a range image of the surface, and for each pig the three views were integrated to produce a complete 3-D mesh.

Sun et al. (2007) developed a stereovision system for measuring the thickness of wheat grains placed on a tray with dimples. The stereopair of images was obtained using a single digital camera, which moved from the first viewpoint along a rail to a second position after acquisition of the first image; therefore, measurements were not taken in real time. The stereo images featured pixel dimensions of about $0.05 \mathrm{~mm}$. The thickness of the grains were mostly between $1 \mathrm{~mm}$ and $3 \mathrm{~mm}$. Using the 95\% quantile of the thickness measurements, the authors reported a RMSE of automatic stereo measurement of grain thickness compared with manual measurement of $0.12 \mathrm{~mm}$ for the large grain group and 0.17 $\mathrm{mm}$ for the small grain group.

With the VI method, the 3-D object is reconstructed from several 2-D silhouettes by back-projecting them from the corresponding viewpoints and intersecting the resulting solid cones (cylinders instead of cones if the orthographic projection simplification is assumed). Segmentation of the silhouettes from the rest of the image and combination with silhouettes taken from different views provides a strong cue for image understanding. An advantage of the VI method compared with stereovision is that the computation time is reduced because it is not necessary to

\footnotetext{
${ }^{4}$ In fact, the laser distance interferometer is the current international standard for length measurements.
} 
find matching points between images. Another advantage is that silhouettes can usually be obtained with simple and robust image-processing techniques, particularly with controlled background. Fig. 6 shows two 2-D silhouettes, $S_{1}$ and $S_{2}$, obtained by taking pictures of the object $\mathrm{O}$ from two different viewpoints, $\mathrm{P}_{1}$ and $\mathrm{P}_{2}$, which correspond to the principal points of the cameras. The silhouettes and viewpoints form cones $C_{1}$ and $C_{2}$. The silhouettes are conical or perspective projections of the object viewed from the principal points. The intersection of the cones is denoted $R$; the object $O$ in Fig. 6 is a cone, surrounded by the region $R$. If we work with several silhouettes taken from different viewpoints, the region $R$ will approximate the shape of $O$. The region $R$ reconstructs the $3-D$ shape of $O$ owing to virtual small cubes called voxels ${ }^{5}$ or cubic pixels. In this way, a horizontal thin layer of the object is projected as horizontal thin lines on the silhouettes at the same height as the layer.

Imou et al. (2006) used a simplified VI method to reconstruct the 3-D shape of strawberries. Their simplification involved reconstructing the strawberries from orthographic silhouettes. Orthographic silhouettes correspond to parallel rather than conical projections, and this simplification is useful when the objects being inspected are small compared with their distance from the camera, as in the case of strawberries. The authors used nine silhouettes, obtained with one camera and nine mirrors, in a desktop configuration. To quantify the difference between the contours obtained by the VI method and with the reference laser scanner, they assigned the term position error to the distance from a point on a contour line obtained by VI to the nearest point on the contour line obtained by the laser scanner for the same height in the sample. For $98.3 \%$ of the fruits, the positional RMSEs in the reconstructed contour were between $0.5 \mathrm{~mm}$ and $2 \mathrm{~mm}$, and there was no relationship between the strawberry size and the RMSEs.

Chalidabhongse et al. (2006) used the VI method to classify mangoes in three size classes. They used four silhouettes, each of which was obtained with one of four cameras. They estimated the volume by counting the number of voxels belonging to the fruit. Using the known calibration grid size, they were able to calculate the volume of the fruits. They obtained CVs of $7.3 \%, 5.5 \%$, and $13.1 \%$ with the reference laboratory instruments and $7.9 \%$, $4.3 \%$, and $14.6 \%$ with the vision system for the smallest, intermediate and largest mangoes, respectively. They concluded that although the vision system gave bigger variations than the laboratory reference instrument, it was more efficient in terms of speed and time.

Lee et al. (2006) used the VI method but they did not obtain different silhouettes using mirrors, as done by Imou et al. (2006), or several cameras, as performed by Chalidabhongse et al. (2006). Instead, they placed the inspected object on a turntable. By rotating the turntable at a fixed angular interval, a fixed camera generated a series of silhouettes from different directions. ${ }^{6}$ In their mathematical model, each silhouette was treated as a cross-section of the object taken at a specific angular position. The system was developed to measure surface area and volume of fresh produce. To assess the volume measurement accuracy of their vision system, the authors performed a comparison with a reference instrument based on Archimedes' principle, on cantaloupes, strawberries, apples, and tomatoes. For apples, they obtained a RMSE of $6 \mathrm{ml}$ and a RMSPE of $1.9 \%$. They concluded that the precision of their method depended on the angular interval of the imaging system, namely the number of

\footnotetext{
5 The term 'voxel' is a contraction of the words volumetric and pixel.

6 Based on the concept of relative movement, for the inspection of the different sides or faces of an object, there are two alternatives: One is that the viewer revolves around the static object, and the other is fixing the position of the viewer and rotating the object in the viewer's field of view. Lee et al. (2006) followed the second approach.
}

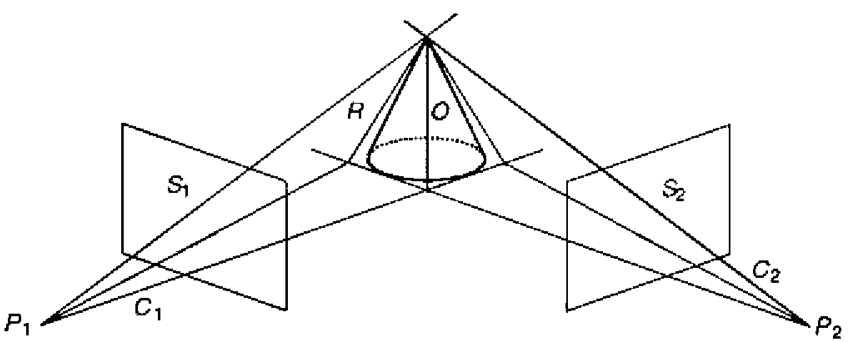

Fig. 6. Principle of the volume intersection method. Reprinted with permission from (Imou et al. 2006), 2006 ASABE.

viewing positions, as well as on the concavities of the object examined.

\subsubsection{Active 3-D machine vision techniques}

In the literature, the terms structured lighting and triangulation laser range finding (the latter of which is sometimes referred to as laser scanning) are often treated as separate methods. Nevertheless, according to Besl (1989), both techniques are particular cases of the same principle of active triangulation. In this paper, we have used this latter criterion, so we use the terms of structured lighting and triangulation laser range finding interchangeably.

For 3-D surface modeling, an alternative approach to stereovision is the projection of structured light, that is, spatially modulated light, onto a fruit. With this method the point matching problem is simplified, and it has the added advantage that only one camera is required. A structured light system uses the projection of a light pattern (plane, grid, or more complex shape) at a known angle onto an object. The most commonly used light pattern is generated by dispersing a laser light beam into a plane or sheet of light. ${ }^{7}$ When the sheet of laser light intersects the surface of the object, a bright line of light can be seen on the surface of the object. By viewing with a camera the line of light from an angle (Fig. 7), the observed distortions in the line can be translated into height variations based on triangulation.

Hatou et al. (1996) used a triangulation laser range finder for constructing the 3-D shape of tomato fruits as they traveled on a conveyor belt beneath the range finder or scanner. For the starting point, they built a reference or ideal tomato shape from measurements obtained using the same laser range scanner. The inspected shape of each fruit was compared with the reference shape, and the differences between the two shapes were used for classification. This was performed using an intelligent classifier system, which included neural networks and expert systems. The authors found that the grading results of their system were similar to those achieved by a skilled human inspector. The disadvantage was that the method was time-consuming - it took $5 \mathrm{~s}$ to classify each tomato.

Sakai and Yonekawa (1992) developed a structured light system for measuring the volume of soybean seeds. They projected a plane of light onto the soybean sample, which was supported by a needle. The plane of light was created by deflecting a laser beam with the lateral faces of a prismatic mirror rotating at high speed. Using cylindrical coordinates, they developed an equation for calculating the seed volume. They measured a large number of seeds, equally distributed among six size groups. Using their method, the volumes had CVs ranging from $5.7 \%$ for the larger seeds to $13.8 \%$ for the smaller. In general, the $\mathrm{CV}$ increased as the seed size decreased. Chen et al. (1989), working on cereal grains, developed an image

\footnotetext{
${ }^{7}$ An easy way of achieving this dispersion or 'fanning out' is by using a cylindrical lens.
} 


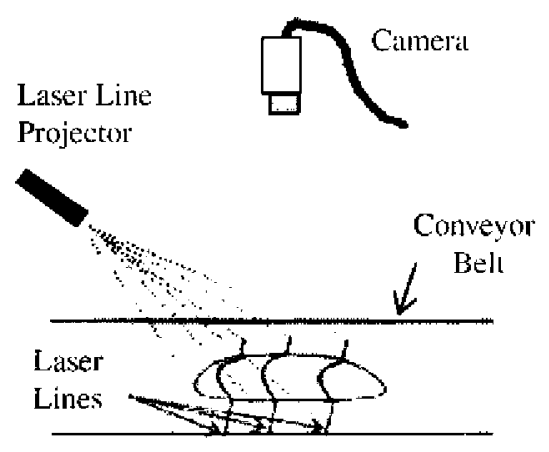

Fig. 7. Active triangulation: projection of a simple structured light pattern consisting of three laser lines onto a piece of food. Reprinted with permission from (Lee et al., 2003), 2003 SPIE.

analysis system with the ability to acquire and combine 3-D laser range data and 2-D camera contour extracted images. The range finder was used to acquire one single cross-section profile at the midpoint of each grain. Based on the images acquired by the laser range finder and the CCD camera contour extractor, a set of kernel feature parameters with the potential to be used for disambiguation among various grains was selected. They obtained a CV of $0.6 \%$ for a parameter computed from the laser range data and that was closely related to grain thickness. To avoid the need for manual positioning of grains in the method of Chen et al. (1989), Thomson and Pomeranz (1991) used a triangulation laser range finder for scanning multiple height profiles of wheat kernels, instead of the single height profile scanned by Chen et al. (1989), which allowed 3-D grain surface reconstruction. However, their system did not include a CCD camera. The necessary boundary planar image was obtained from an intensity image obtained by the laser range finder. To understand this, it is sufficient to say that the intensity images of the laser range finders contain the energy of the emitted laser signal, which is reflected back in the direction of the sensor. The authors did not report the precision of their system.

Lee et al. (2001), and Lee et al. (2003), proposed an algorithm (3-D approach), which combined active triangulation with 2-D measurement to reconstruct the 3-D surface of oyster meat (although the present review deals with fruits and vegetables, this research on an animal produce like the oyster meat is included for comparison purposes). The final objective was to grade the oyster meat pieces according to their unit volume. The authors compared the 3-D approach with a 2-D approach which computed volume from projected area measured in pixels. The authors reported that the main source of error in the 2-D algorithm volume calculations were due to the inability to discriminate between two pieces of oyster with the same projected area but with different heights and therefore volumes. They reported that the 3-D approach reduced the volume measurement error by $41 \%$; the RMSE of the 3-D approach was $0.7 \mathrm{ml}$.

\subsubsection{Discussion}

Hryniewicz et al. (2005) obtained satisfactory results with their stereovision desktop system, using the assumption of circular fruit or vegetable cross-section. The performance of the system would be expected to be less good with produce that is elliptical in cross section, such as many kiwifruits, some cultivars of apple, and mangoes.

Among the three mentioned studies that use the VI method, the most expensive is the model developed by Chalidabhongse et al. (2006), because it uses four cameras; the models of Imou et al. (2006) and Lee et al. (2006) only require one camera. On the other hand, the slowest system would be that developed by Lee et al.
(2006), because it requires some time for turning of the rotary table to be completed. Considering cost and speed, we conclude that the preferred system should be that developed by Imou et al. (2006). A comparison of measurement accuracy should be restricted to the systems of Imou et al. (2006) and Lee et al. (2006), because RMSE values have been reported for both, whereas the system by Chalidabhongse et al. (2006) reports results as CVs. Regardless, the latter system seems the worst of the three, according to the CV of $14.6 \%$ obtained for mangoes of the first class (no overall average $\mathrm{CV}$ can be calculated, because the authors did not report the number of fruits in each of the three size groups). Restricting the comparison to the other two systems, we find that Imou et al. (2006) did not include the value of RMSPE, and the comparison between both systems cannot be done according to RMSE because the RMSEs correspond to different magnitudes (linear dimension in the work by Imou et al. and volume in the work by Lee et al.). Nevertheless, focusing on the best-shaped strawberries, it is possible to calculate a rough estimate of the RMSPE using a figure in the paper by Imou et al., and a mean equatorial diameter of $31 \mathrm{~mm}$ can be estimated. Dividing $0.77 \mathrm{~mm}$ (the RMSE for the bestshaped berries) by $31 \mathrm{~mm}$, a value of $2.5 \%$ is obtained as a rough estimate of RMSPE for Imou system. This method of computing the RMSPE is not valid from an academic or statistical point of view, but it is the only way to compare these two systems with the information available. As the RMSPE obtained by Lee et al. (2006) was $1.9 \%$, it can be concluded that the system of Lee et al. (2006) is more accurate than that of Imou et al. (2006).

In terms of hypothetical on-line application, Chalidabhongse et al. (2006) reported no details on how their desktop concept could be incorporated into a packing line. According to the image acquisition set-up described by these authors, it would be straightforward to position three of the cameras in an on-line assembly, but it is not clear how the fourth camera could be mounted in a typical illumination chamber of an on-line machine vision system. Imou et al. (2006) reported a processing time of $1 \mathrm{~s}$ for the shape assessment of one strawberry. For a typical fruit sorter, this would represent a rather low throughput. However, the final goal of their work was to develop part of a comprehensive strawberry packing house, in which the berries would be harvested by a robot arm and placed on the table surrounded by mirrors for measurement and subsequent packing. This means that the time to measure one berry ( $1 \mathrm{~s}$ ) should be increased to include the placing of the strawberry on the 'measurement table' and subsequent lifting, as both operations are performed by the robot arm. Lee et al. (2006) reported that the silhouette of each image was extracted at the frame rate, depending on the speed of turntable rotation; the volume and surface area measurements were reported before the object was replaced, but the authors did not indicate how to translate their system to an on-line sorting machine.

Of the active 3-D machine vision systems described, only those of Hatou et al. (1996) and Lee et al. (2001, 2003) correspond to online implementation. The system by Hatou et al. (1996) was particularly slow, and these authors did not specify the precision of their system. The system by Lee et al. (2001, 2003) featured a conveying speed of 5 oyster meat pieces/s-lane.

From the point of view of industrial applicability, active 3-D machine-vision-based technology is more robust than its passive 2-D and 3-D counterparts. The main reason for this is the simplified lighting and camera adjustments utilized by active 3-D systems for taking images of the objects. By contrast, in the passive systems the lighting adjustments and camera calibration must be precise for a range of gray levels in the inspected object, and parts of these objects will be outside of the detectable gray-scale range (Lee et al., 2003). One of the main applications of 3-D machine vision in the future, other than volume estimation, will be in surface area and 3-D shape assessments. 


\subsection{Other techniques}

Kanali et al. (1998) developed a prototype artificial retina machine vision system. In conventional digital image analysis techniques for the inspection of agricultural produce, the image of the produce is first recorded by a video-camera, then the video signals are digitized and finally analyzed. However, with the artificial retina system there is a direct transfer of the acquired information to the processing algorithm, which can, for example, be the chargesimulation method (CSM). ${ }^{8}$ Although most of the active 3-D machine vision methods depend on digital image analysis, which often involves pre-processing operations such as noise reduction, enhancement operations such as edge detection, feature extraction, and matching, the use of the artificial retina with the CSM requires no digital image analysis. This represents an advantage because digital image analysis often requires specialized and expensive software to successfully process the images. Another advantage of the artificial retina concept is that the photosensors used in this device are cheaper than any of the CCD or CMOS sensors equipped with video-cameras. A disadvantage of the artificial retina concept is that it cannot calculate fruit diameters, only fruit volume (Gall et al., 1998). The prototype artificial retina machine vision system developed by Kanali et al. (1998) transferred the data obtained to a retina model, which was identical to the 'hardware' prototype. This prototype was basically comprised of a hemispherical chamber (artificial retina) equipped with many photosensors, or sensory cells. One of these elements was located at the center of the Fresnel lens placed at the base of the hemisphere, another was placed at the pole of the hemisphere (Fig. 8), and the remainder were uniformly distributed on several circumferences on the hemisphere surface at different heights from the base. The photosensors measured the distribution of light intensity based on images generated by different sizes of a 3-D object placed in the retina. The function of sensory cells was to obtain primary shape information, which would then be compressed using the CSM. To assess the performance of their system, Kanali et al. (1998) conducted tests on oranges and eggplants. They obtained overall size classification rates of $99 \%$ and $74 \%$ for oranges and eggplants, respectively. One possible reason for a higher classification performance for oranges was that the size variability of oranges was greater than that among the eggplants.

Hoffmann et al. (2005) aimed to sort potato tubers according to their starch content calculated from density measurements and used an optoelectronic device to measure the volume of the tubers. The details of the machine vision system are unclear from the scarce description reported in their paper, so this system has been included in the "Other techniques" group. The optoelectronic sorter consisted of a ring-shaped basic body with four cameras. The tubers were passed individually through the basic body, while the camera system recorded their geometric dimensions in three axes and the surface of the tubers. A processor calculated the volume of the tuber using the elliptical integrals from the data supplied by the camera. The authors obtained a CV of $1 \%$ in tuber volume determination. This high repeatability, together with the high precision achieved in the mass measurement device, made starch sorting in three classes possible.

De Waal et al. (1988) used microwave technology for on-line weight estimation of apples and oranges. Their approach was based on the effect of fruit water content on the resonant frequency of a resonant waveguide cavity. As apples and oranges consist of more than $80 \%$ water, the determination of the volume of water represented an accurate measure of fruit volume, and therefore weight. They measured the microwave attenuation caused by

\footnotetext{
${ }^{8}$ The CSM is a numerical method used to obtain an approximate solution to the equation of Laplace.
}

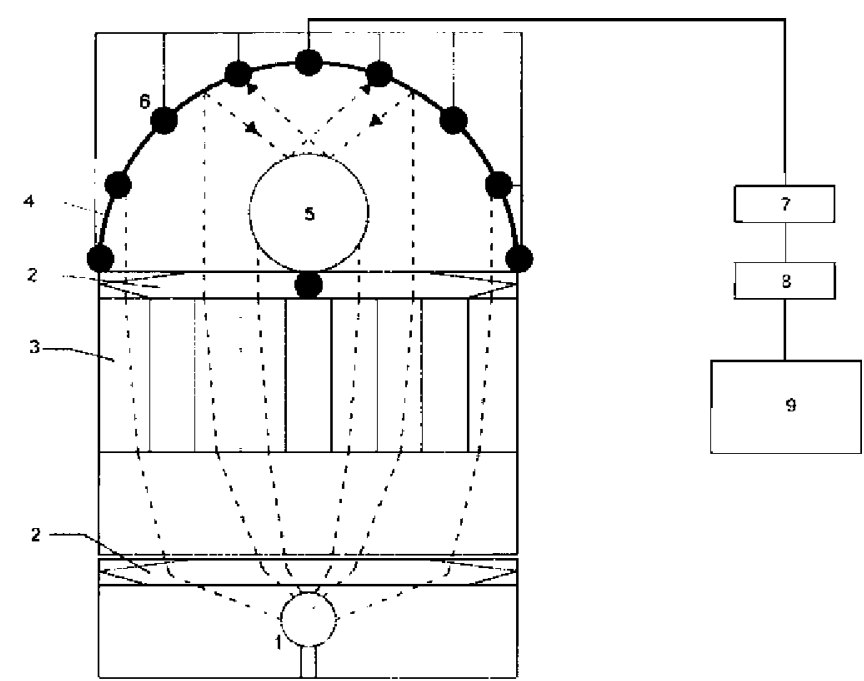

Fig. 8. Configuration of the artificial retina machine-vision system (redrawn from Kanali et al., 1998). The numbers refer to: 1, tungsten halogen lamp; 2, Fresnel lenses; 3 , light beam conditioner; 4 , artificial retina; 5 , inspective fruit; 6 , CdS photo sensor; 7, data transfer unit; 8, A/D converter; and 9, computer.

absorption in the fruit, and reported that the power levels used in their tests were too low to cause damage to the fruit. In their tests, better results were obtained for oranges than apples, owing to the lack of symmetry of the latter. Overall, they obtained accuracies of about $95 \%$ (they did not specify the statistical parameter computed) for both fruits, for an operating speed of $5 \mathrm{~m} / \mathrm{s}$ (Fig. 9).

Andaur et al. (2004), who used MRI to measure wine grapes, developed reconstruction techniques for 3 -D representation of berry clusters. Size distribution of berries is important to predict extractability in grapes because the wine-making parameter of extractability is a function of the skin-to-flesh ratio, so it is inversely proportional to the volume of the berries. To obtain the reference volume of single berries, the authors used a vernier caliper to

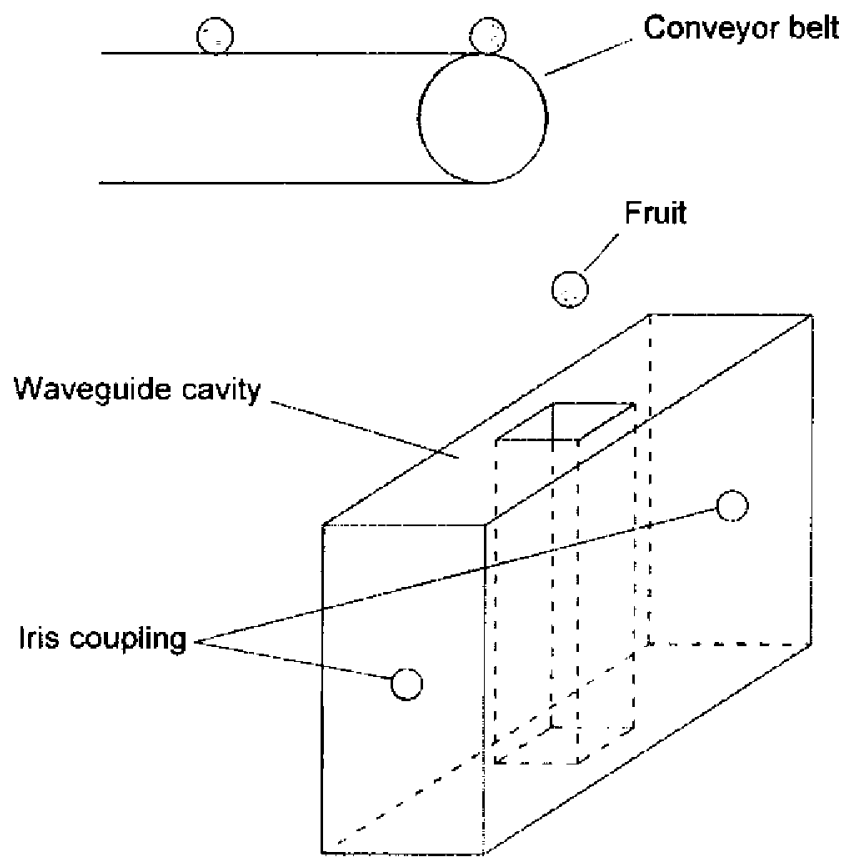

Fig. 9. Setup of the on-line microwave system for fruit volume determination (redrawn from De Waal et al., 1988). 
measure the berry equatorial diameter and computed the reference volume using the equation for the volume of a sphere, because the grapes tested were quite spherical. They obtained a mean absolute percentage error (MAPE) of $3.15 \%$ for the volume of single berries.

Maisl et al. (2006) used CT to determine the 3-D structure of sugar beet seeds. The inspection system setup comprised a sealed microfocal X-ray tube, a turntable with a sample holder, a flat panel X-ray detector and a network of four PCs for data acquisition, reconstruction and image processing. To characterize the seeds the authors used an automatic segmentation procedure to separate the different seed materials or layers. Their approach for seed volume segmentation consisted of scanning central slices. Within each slice, the one-dimensional edge detection was performed on gray-value profiles, where the profiles represented radial lines. Merging the segmentation results of all radial lines into one image generated segmentation of the whole central slice, and merging all central slices into one volume generated segmentation of the whole seed volume. The final step of the automatic image processing sequence consisted of computing features such as minimum and maximum diameters. The system was able to measure the geometrical traits of seeds with a mean diameter of $3.5 \mathrm{~mm}$ with an accuracy of better than $0.1 \mathrm{~mm}$. The authors did not report whether this value of accuracy corresponds to RMSE or another statistical parameter. The throughput of the machine was 1000 seeds/h.

\subsection{General system comparison}

We have now discussed many different size sensing techniques. For convenience, a summary of some of the main features of some of these techniques is shown in Table 1. Only those techniques for which an RMSE value is available have been included in Table 1. Likewise, a summary of suitable techniques for on-line size determination of different fruits and vegetables is shown in Table 2, and a compilation of references on each dimension-sizing technique has been included in Table 3 .

Of all the systems described above, 2-D machine vision-based systems are the most widespread because, in addition to size and shape, they are used to classify produce according to surface color and external defects. In general, the technologies of 2-D machine vision and electronic weighing are suitable for any produce (Table 2). Machine vision sorters are more aggressive with the produce than electronic weight sizers, since the fruit rotation generated in the first case to inspect all the surface of the fruit can cause abrasion damage to the fruit skin, particularly at high speeds. On the other hand, fruit rotation is necessary for viewing the whole fruit surface and allow sorting by colour or by number and size of external blemishes. The only limitation to the applicability of machine vision to horticultural produce inspection would be the appearance of reflections that tend to saturate CCD and CMOS sensors of videocameras. Usually, this is circumvented by using indirect lighting, and, where necessary (e.g. for inspection of citrus, apples, and other waxed fruits), by mounting filters in the optics of the video-camera. Another option would be the utilization of charge injection device (CID) sensors in the cameras, which do not saturate as easily as CCD or CMOS sensors.

Other than the machine referred to in Section 6.2, on-line ultrasound sizing systems seem to have had little success. However, the portable ultrasonic instrument developed by Laing et al. (1995) seems a good option for non-destructive measurements in the field, having the advantage of higher speed (Table 1 ) over the air pycnometer system developed by Iraguen et al. (2006). However, the two portable systems of Laing et al. (1995) and Iraguen et al. (2006) are not fully comparable, because they are designed for different produce. Thus, the volume of a grape cluster, the produce




Table 2

Suitable size determination techniques for on-line inspection of fruits and vegetables.

\begin{tabular}{|c|c|c|c|}
\hline Fruit group & Potential sizing technology & $\begin{array}{l}\text { Sizing technology } \\
\text { currently used (as to 2008) }\end{array}$ & $\begin{array}{l}\text { Sizing parameter provided by } \\
\text { EU marketing standards }{ }^{a}\end{array}$ \\
\hline $\begin{array}{l}\text { Citrus (Orange, lemon, tangerine, grapefruit, } \\
\text { lime) }\end{array}$ & 2D, 3D machine vision; electronic weighing & $\begin{array}{l}\text { 2D machine vision, } \\
\text { electronic weighing }\end{array}$ & MDES \\
\hline Apple & 2D, 3D machine vision; electronic weighing & $\begin{array}{l}\text { 2D machine vision, } \\
\text { electronic weighing }\end{array}$ & MDES, FW \\
\hline Pear & 2D, 3D machine vision; electronic weighing & $\begin{array}{l}2 \mathrm{D} \text { machine vision, } \\
\text { electronic weighing }\end{array}$ & MDES \\
\hline Tomato ('Beefsteak' type) ${ }^{b}$ & 2D, 3D machine vision; electronic weighing & $2 \mathrm{D}$ machine vision & MDES \\
\hline $\begin{array}{l}\text { Stone fruits (Peach, nectarine, apricot, plum, } \\
\text { cherry) }\end{array}$ & 2D, 3D machine vision; electronic weighing & $\begin{array}{l}\text { 2D machine vision, } \\
\text { electronic weighing }\end{array}$ & $\begin{array}{l}\text { MDES (Peach, nectarine, apricot, } \\
\text { plum, cherry), } C \text { (Peach, nectarine) }\end{array}$ \\
\hline $\begin{array}{l}\text { Very elongated (Zucchini, cucumber, carrot, } \\
\text { 'Lamuyo' pepper, aubergine, papaya) }\end{array}$ & $\begin{array}{l}\text { 2D, 3D machine vision; optical ring sensorc }{ }^{c} \text { (Gall, } \\
\text { 1997; Moreda, 2004); electronic weighing }\end{array}$ & $\begin{array}{l}\text { Electronic weighing, 2D } \\
\text { machine vision }\end{array}$ & FW (Cucumber, carrot), MDES (Carrot) \\
\hline $\begin{array}{l}\text { Moderately elongated (Kiwifruit, mango, } \\
\text { avocado, 'California Wonder' bell pepper) }\end{array}$ & $\begin{array}{l}\text { 2D, 3D machine vision; optical ring sensorc; } \\
\text { electronic weighing }\end{array}$ & $\begin{array}{l}\text { Electronic weighing, 2D } \\
\text { machine vision }\end{array}$ & FW \\
\hline Large and heavy (Melon, watermelon) & $\begin{array}{l}\text { 2D, 3D machine vision; electrical capacitance (Kato, } \\
\text { 1997); electronic weighing }\end{array}$ & Electronic weighing & $\begin{array}{l}\text { FW (Melon, watermelon), MDES } \\
\text { (Melon) }\end{array}$ \\
\hline Bulbs (Onion, garlic) & 2D, 3D machine vision; electronic weighing & $\begin{array}{l}\text { Electronic weighing, } \\
\text { mechanical diameter } \\
\text { sizing }\end{array}$ & MDES \\
\hline $\begin{array}{l}\text { Leafy round vegetables ('Iceberg' lettuce, } \\
\text { cabbage, cauliflower, broccoli) }\end{array}$ & 2D, 3D machine vision ${ }^{d}$ electronic weighing & Electronic weighing & FW (Lettuce), MDES (Cauliflower) \\
\hline \multicolumn{4}{|c|}{$\begin{array}{l}\text { EU: European Union; MDES: maximum diameter of the equatorial section; FW: fruit weight; C: circumference. } \\
\text { b Whenever the applicable marketing standard stipulates the MDES as the sizing parameter for 'beefsteak' tomatoes, electronic weighing should be discarded as a sizing } \\
\text { Iternative for these tomatoes, due to the low correlation between MDES and FW featured by these fruits (Sargent et al., 1988). } \\
\text { c Since the optical ring sensor generates a convex hull of each cross-section scanned, the pepper fruit volume measurements made by the optical ring sensor would be } \\
\text { verestimated, due to the presence of concavities in the cross-sections of these fruits. } \\
\text { d 'Iceberg' lettuces are usually film-wrapped before being sized. Due to the difficulty of achieving a perfect fit of the film onto the external surface of the lettuce, 2D and 3D } \\
\text { lachine vision would probably overestimate the size of these vegetables. On the other hand, the plastic wrapping-film provokes reflections that tend to saturate the CCD or } \\
\text { MOS video-camera sensors. This is why currently the sizing of 'iceberg' lettuces is entrusted to electronic weight sizers (furthermore, presumably the correlation between } \\
\text { IDES or volume and FW is not very high for this produce). }\end{array}$} \\
\hline
\end{tabular}

Table 3

Types of technologies and relevant literature on produce dimension-sizing.

\begin{tabular}{|c|c|}
\hline Technology & References \\
\hline SBMVGBFOC $^{\mathrm{a}}$ : Optical ring sensor & Gall (1997), Gall et al. (1998), Moreda (2004), Moreda et al. (2007) \\
\hline SBMVGBFOC: Electrical capacitance & Kato (1997) \\
\hline SBMVGBFOC: Helmholtz resonator & Nishizu et al. (2001) \\
\hline Blocking of light ${ }^{\mathrm{b}}$ & Iwamoto and Chuma (1981), Fon et al. (1990), Chen et al. (1992), Hahn (2002) \\
\hline Ultrasound TOF & Miller (1993), Laing et al. (1995) \\
\hline 2D machine vision & $\begin{array}{l}\text { Sarkar and Wolfe (1985), Marchant et al. (1989), Marchant (1990), Miller (1990), Aleixos (1999), Forbes and } \\
\text { Tattersfield (1999b), Bato et al. (2000), Forbes (2000), Aleixos et al. (2002), Sabliov et al. (2002), Blasco et al. (2003), } \\
\text { etc. }\end{array}$ \\
\hline 3D machine vision: Passive stereovision & Hryniewicz et al. (2005), Sun et al. (2007) \\
\hline $\begin{array}{l}\text { 3D machine vision: Volume intersection method } \\
\text { (Shape from silhouettes) }\end{array}$ & Chalidabhongse et al. (2006), Imou et al. (2006), Lee et al. (2006) \\
\hline 3D machine vision: Active triangulation & $\begin{array}{l}\text { Chen et al. (1989), Sakai and Yonekawa (1992), Thomson and Pomeranz (1991), Hatou et al. (1996), Lee et al. (2001), } \\
\text { Lee et al. (2003) }\end{array}$ \\
\hline Computed tomography $(\mathrm{CT})$ & Maisl et al. (2006) \\
\hline Magnetic resonance imaging (MRI) & Andaur et al. (2004) \\
\hline Artificial retina & Kanali et al. (1998) \\
\hline Microwave & De Waal et al. (1988) \\
\hline
\end{tabular}

a SBMVGBFOC: Systems based on measuring the volume of the gap between the fruit and an outer casing.

b The optical ring sensor also belongs to this category.

c TOF: Time of flight.

tested with the air pycnometer, cannot be measured using the ultrasonic inverted tripod.

The optical ring sensor system (Gall, 1997) has a good performance on elongated produce. It does not require correctly oriented fruits for volume determination but it does for axes determination. For accurate volume determination, the only requirement is that the fruits cross the ring with no swinging movement. The electrical capacitance method (Kato, 1997) accurately measured the volume of watermelons, but it had the disadvantage of requiring fruit orientation.

of the 2-D machine-vision systems described, those by Aleixos et al. (2002), Forbes and Tattersfield (1999b), and Blasco et al. (2003) can be considered good options, sharing the advantage of not requiring fruit orientation. Another sophisticated system, with a singular design that differs from other systems in that it does not need singulation across the line, is that developed by Marchant (1990). The system developed by Sabliov et al. (2002) delivers good results but is a desktop configuration.

Among 3-D machine-vision systems, those of the passive type (stereovision, VI method) have not yet been implemented on-line, whereas the active triangulation systems have. In applications in which, in addition to volume determination, surface area is of interest, 3-D shape recovery is particularly importance and 3-D methods can have an important role. If only volume measurement is needed, the 2-D machine vision method by Forbes (2000) is a good option. Another way of exploiting 3-D machine vision is by 
combining it with multispectral imaging (Lathulière et al., 2006). These authors developed a 3-D multispectral scanner comprised of an LCD projector and a multispectral camera. The setup is similar to the system depicted in Fig. 7, with the main difference of the type of structured light and camera used. Given the remarkable success that multispectral cameras are having in our days, -they are very useful in detecting fruit blemishes-, the approach by Lathulière et al. reveals as a very interesting option for the future, since it allows the reconstruction and association of a complete reflective spectrum to each 3 -D point.

of the systems referred to in Section 6.6 (Other techniques), CT and MRI are expensive techniques, the use of which does not seem justified for size determination alone. The waveguide cavity concept reported by De Waal et al. (1988) is likely to have been associated with some technical or cost problems because there have been no additional reports on this system. Although interesting, the artificial retina machine-vision system of Kanali et al. (1998) has the disadvantage of being a desktop system. These authors concluded that more work needs to be done before the technique can be used for automated inspection of fruits and vegetables.

\section{Conclusions}

This review focuses on different electronic-based approaches used for horticultural produce size estimation, with emphasis on the dimensional-type approaches. The benefits of fruit size assessment have been described. A comprehensive classification of the different systems available has been proposed. The different systems identified are compared in terms of their versatility, precision and throughput. Although the challenge of on-line determination of diameters, projected area and perimeter is considered to have been overcome, on-line volume determination of irregularly shaped produce both at high speed, and sufficiently accurate enough to allow subtle SSC density-based sorting, has only become available in the past few years.

Among the different techniques reviewed here, 2-D machine vision and electronic weighing are currently the most widespread techniques used in fresh produce packing houses. The main reason for the prevalence of 2-D machine-vision systems over other systems is that it allows classification of fruits according to their surface color and external defects; associated with this is the rapidly decreasing price of CCD and CMOS sensors. Nevertheless, we expect that $3-D$ imaging systems will be increasingly used to supplement 2-D machine-vision technology. Off-the-shelf smart 3-D cameras are now available for food inspection. However, it seems reasonable to predict that the introduction of 3-D machine-vision systems in horticultural produce packing houses will be slower than in the food industry owing to the low unitary value of produce. As has occurred before (for example, with brix sensing), some markets will lead the introduction of 3-D surface data inspection, whereas other markets and/or countries will still have to wait to benefit from progress in this field.

A good method of fruit 3-D surface reconstruction, from which volume and surface area can be calculated, is the combination of height profiles obtained from a range sensor with a 2-D object image boundary obtained from a solid-state camera (brightness image) or from the range sensor itself (intensity image). However, one of the most promising technologies in this field is 3-D multispectral scanning, which combines multispectral data with 3-D surface reconstruction.

\section{Appendix: basic statistics used in precision quantification}

Here, we outline the mathematical expressions of some basic statistics mentioned in this review. These include: the root mean squared error (RMSE), Eq. (2), and the root mean squared percent- age error (RMSPE), Eq. (3), (Forbes, 2000); the coefficient of variation (CV), Eq. (4); the mean absolute error (MAE), Eq. (5); the mean absolute percentage error (MAPE), Eq. (6), (Chen et al., 2003); and the relative error, Eq. (7).

RMSE $=\sqrt{\frac{1}{n} \sum_{i=1}^{n}\left(x_{\mathrm{ai}}-x_{\mathrm{pi}}\right)^{2}}$

RMSPE $=\sqrt{\frac{1}{n} \sum_{i=1}^{n}\left(\frac{x_{\mathrm{ai}}-x_{\mathrm{pi}}}{\mathrm{x}_{\mathrm{ai}}}\right)^{2}} \cdot 100$

where $x_{\mathrm{ai}}=i_{\mathrm{th}}$ actual value; $x_{\mathrm{pi}}=i_{\mathrm{th}}$ predicted value; $n=$ number of samples.

$\mathrm{CV}(\%)=\frac{\sigma}{\overline{x_{\mathrm{p}}}} \cdot 100=\frac{\sqrt{\frac{1}{n} \sum_{i=1}^{n}\left(x_{\mathrm{pi}}-\overline{x_{\mathrm{p}}}\right)^{2}}}{\frac{1}{n} \sum_{i=1}^{n} x_{\mathrm{pi}}} \cdot 100$

where $\sigma=$ standard deviation of a set of predicted values; $x_{\mathrm{pi}}=i_{\mathrm{th}}$ predicted value; $\overline{x_{p}}=$ arithmetic mean of the set of predicted values; $n=$ number of samples in the set.

$\mathrm{MAE}=\frac{1}{n} \sum_{i=1}^{n}\left|x_{\mathrm{ai}}-x_{\mathrm{pi}}\right|$

MAPE $=\frac{1}{n} \sum_{i=1}^{n} \frac{\left|x_{\mathrm{ai}}-x_{\mathrm{pi}}\right|}{x_{\mathrm{ai}}} \cdot 100$

where $x_{\mathrm{ai}}=i_{\mathrm{th}}$ actual value; $x_{\mathrm{pi}}=i_{\mathrm{th}}$ predicted value; $n=$ number of samples.

Relative error $(\%)=\frac{\overline{x_{\mathrm{a}}}-\overline{x_{\mathrm{p}}}}{\overline{x_{\mathrm{a}}}} \cdot 100$

where $\overline{x_{\mathrm{a}}}=$ arithmetic mean of a set of actual values; $\overline{x_{\mathrm{p}}}=$ arithmetic mean of the set of predicted values.

\section{Acknowledgments}

The authors wish to thank Professor William M. Miller from the University of Florida (U.S.A.) and Professors Constantino Valero and Belén Diezma from Universidad Politécnica de Madrid (Spain) for their help with the compilation of bibliography cited in this review.

\section{References}

Affeldt Jr., H.A., Brown, G.K., Brusewitz, G.H., Delwiche, M.J., Hetzroni, A., Kranzler G.A., et al., 1994. Dimension, shape and surface texture measurement on agricultural commodities. In: Proceedings of the BARD International Workshop on Nondestructive Technologies for Quality Evaluation of Fruits and Vegetables. ASAE, St. Joseph, Mich., USA, pp. 50-62.

Aggarwal, J.K., Chien, C.H., 1989. Chapter 2: 3-D structures from 2-D images. In: Sanz, J.LC. (Ed.), Advances in Machine Vision. Springer-Verlag Inc., New York, NY, pp. 64-121.

Aleixos, N. 1999. Desarrollo de técnicas de visión artificial, utilizando procesadores digitales de señal. Aplicación a la detección de defectos en frutas en tiempo real. Ph.D. Dissertation. Universidad Politécnica de Valencia, Spain. Development of machine vision techniques, using digital signal processors. Application to realtime fruit defect detection.

Aleixos, N., Blasco, J., Navarrón, F., Moltô, E., 2002. Multispectral inspection of citrus in real-time using machine vision and digital signal processors. Computers and Electronics in Agriculture 33 (2), 121-137.

Aloimonos, J., 1988. Visual shape computation. Proceedings of the IEEE 76 (8), 899916.

Andaur, J.E., Guesalaga, A.R., Agosin, E.E., Guarini, M.W., Irarrázaval, P., 2004 Magnetic resonance imaging for nondestructive analysis of wine grapes. Journal of Agricultural and Food Chemistry $52(2), 165-170$

Bato, P.M., Nagata, M., Cao, Q., Hiyoshi, K., Kitahara, T., 2000. Study on sorting system for strawberry using machine vision (Part 2). Journal of the Japanese Society of Agricultural Machinery 62 (2), 101-110. 
Battle, J., Mouaddib, J., Salvi, J., 1998. Recent progress in coded structured light as a technique to solve the correspondence problem: a survey. Pattern Recognition $31(7), 963-982$

Besl, P.J., 1989. Chapter 1: active optical range imaging sensors. In: Sanz, J.L.C. (Ed.), Advances in Machine Vision. Springer-Verlag Inc., New York, NY, pp. 1-63.

Blais, F., 2004. Review of 20 years of range sensor development. Journal of Electronic Imaging $13(1), 231-240$.

Blasco, J., Aleixos, N., Moltô, E., 2003. Machine vision system for automatic quality grading of fruit. Biosystems Engineering 85 (4), 415-423.

Brosnan, T., Sun, D.-W., 2004. Improving quality inspection of food products by computer vision - a review. Journal of Food Engineering $61(1), 3-16$

Butz, P., Hofmann, C., Tauscher, B., 2005. Recent developments in noninvasive techniques for fresh fruit and vegetable internal quality analysis. Journal of Food Science 70 (9), 131-141.

Chalidabhongse, T., Yimyam, P., Sirisomboon, P., 2006. 2-D/3-D vision-based mango's feature extraction and sorting. In: 9th International Conference on Control, Automation, Robotics and Vision (ICARCV'06), p. 6.

Chen, C., Chiang, Y.P., Pomeranz, Y., 1989. Image analysis and characterization of cereal grains with a laser range finder and camera contour extractor. Cerea Chemistry 66 (6), 466-470.

Chen, R.J.C., Bloomfield, P., Fu, J.S., 2003. An evaluation of alternative forecasting methods to recreation visitation. Journal of Leisure Research 35 (4), 441-454.

Chen, S., Fon, D.-S., Hong, S.-T., Wu, C.-J., Leu, K.-C., Tien, B.-T., et al. (1992). Electrooptical citrus sorter. ASAE Paper No. 923520 . St. Joseph, Mich., USA: ASAE.

Clayton, M., Amos, N.D., Banks, N.H., Morton, R.H., 1995. Estimation of apple fruit surface area. New Zealand Journal of Crop and Horticultural Science 23, 345349

Commission Regulation (European Communities) No. 1799/2001 of 12 September 2001 laying down the marketing standard for citrus fruit. Official Journal L244 $14 / 09 / 2001$, pp. $12-18$

Davenel, A., Guizard, Ch., Labarre, T., Sevila, F., 1988. Automatic detection of surface defects on fruit by using a vision system. Journal of Agricultural Engineering Research 41 (1), 1-9.

Deck, S.H., Morrow, C.T., Heinemann, P.H., Sommer III, H.J., 1995. Comparison of a neural network and traditional classifier for machine vision inspection of potatoes. Applied Engineering in Agriculture 11 (2), 319-326.

De Waal, A., Mercer, S., Downing, B.J., 1988 . On line fruit weighing using a $500 \mathrm{MHz}$ waveguide cavity. IEEE Electronics Letters 24 (4), 212-213.

Doebelin, E.O., 1966. Measurement Systems: Application and Design. Mc Graw-Hill, New York. p. 743

Du, C.-J., Sun, D.-W., 2004. Recent developments in the applications of image processsing techniques for food quality evaluation. Trends in Food Science and Technology 15 (5), 230-249.

Eifert, J.D., Sanglay, G.C., Lee, D.-J., Sumner, S.S., Pierson, M.D., 2006. Prediction of raw produce surface area from weight measurement. Journal of Food Engineering 74 (4), 552-556.

Fon, D.-S., Chen, S., Yang, C.Y. 1990. Size sorting of fruits using atray phototransistors. ASAE Paper No. 907058. St. Joseph, Mich., USA: ASAE.

Forbes, K., 2000. Volume estimation of fruit from digital profile images. Master's thesis. Cape Town, South Africa: University of Cape Town, Department of Electrical Engineering. <www.dip.ee.uct.ac.za/(kforbes/Publications/ msckaf.pdf>. (accessed 30.09.07)

Forbes, K.A., Tattersfield, G.M., 1999a. Volumetric determination of apples using machine vision techniques. Elektron Journal of the South African Institute of Electrical Engineers 16 (3), 14-17.

Forbes, K.A., Tattersfield, G.M., 1999b. Estimating fruit volume from digital images Fifth Africon Conference in Africa: AfriCon, vol. 1. IEEE, Los Alamitos, Cal., USA pp. 107-112.

Francés, J.V., Calpe, J., Soria, E., Martínez, M., Rosado, A., Serrano, A.J., et al., 2000 Application of ARMA modeling to the improvement of weight estimations in fruit sorting and grading machinery. In: International Conference on Acoustics. Speech and Signal Processing, vol. 6. IEEE, Los Alamitos, Cal., USA, pp. 3666 3669 .

Gall, H., 1997. A ring sensor system using a modified polar coordinate system to describe the shape of irregular objects. Measurement Science and Technology 8 (11), 1228-1235

Gall, H., Muir, A., Fleming, J., Pohlmann, R., Göcke, L., Hossack, W., 1998. A ring sensor system for the determination of volume and axis measurements of irregular objects. Measurement Science and Technology 9 (11), 1809-1820.

García-Ramos, F.J., Ortiz-Cañavate, J., Ruiz-Altisent, M., 2004. Evaluation and correction of the mechanical aggressiveness of commercial sizers used in stone fruit packing lines. Journal of Food Engineering 63 (2), 171-176.

García-Ramos, F.J., Valero, C., Homer, I., Ortiz-Cañavate, J., Ruiz-Altisent, M., 2005 Non-destructive fruit firmness sensors: a review. Spanish Journal of Agricultura Research 3 (1), 61-73.

Hahn, F., 2002. Automatic jalapeño chilli grading by width. Biosystems Engineering $83(4), 433-440$

Hahn, F., Sanchez, S., 2000. Carrot volume evaluation using imaging algorithms Journal of Agricultural Engineering Research 75 (3), 243-249.

Hall-Holt, O., Rusinkiewicz, S., 2001. Stripe boundary codes for real-time structured-light range scanning of moving objects. In: Proceedings of the 8th IEEE International Conference on Computer Vision (ICCV 2001), vol. 2, pp. 359366.

Hardin, W., 2006. 3D, advanced technologies make food inspection palatable. $<w w w$.machinevisiononline.org/public/articles/articlesdetails.cfm?id=2827> (accessed 16.01.08).
Hatou, K., Morimoto, T., De Jager, J., Hashimoto, Y., 1996. Measurement and recognition of 3-D body in intelligent plant factory. In: Abstracts of the International Conference on Agricultural Engineering (AgEng). Madrid, vol. 2, pp. 861-862 (Paper No. 96F-027)

Hoffmann, T., Fürll, C., Ludwig, J., 2004. A system for the on-line starch determination at potato tubers. In: Proceedings of the International Conference on Agricultural Engineering (AgEng). Technologisch Instituut vzw, CD-ROM.

Hoffmann, T., Wormans, G., Fürll, C., Poller, J., 2005. A system for determining starch in potatoes online. http://vddb-dt.library.lt/fedora/get/LT-eLABa-0001: J.04 2005 ISSN_1392-1134.V_37.N_2.PG_34-43/DS.002.1.01.ARTIC. (accessed 15.08.08)

Hryniewicz, M., Sotome, I., Anthonis, J., Ramon, H., De Baerdemaeker, J., 2005. 3-D surface modeling with stereovision. In: Hertog, M.L.A.T.M., Nicolaï, B.M., (Eds.), Proceedings of the 3rd International Symposium on Applications of Modeling as an Innovative Technology in the Agri-Food Chain; MODEL-IT 2005. ISHS Acta Horticulturae 674

Imou, K., Kaizu, Y., Morita, M., Yokoyama, S., 2006. Three-dimensional shape measurement of strawberries by volume intersection method. Transactions of the ASABE 49 (2), 449-456.

Iraguen, V., Guesalaga, A., Agosin, E., 2006. A portable non-destructive volume meter for wine grape clusters. Measurement Science and Technology 17 (12), N92-N96.

Iwamoto, M., Chuma, Y., 1981. Recent studies on development in automated citrus packinghouse facility in Japan. Proceedings of the International Society of Citriculture 2, 831-834.

Jahns, G., Nielsen, H.M., Paul, W., 2001. Measuring image analysis attributes and modeling fuzzy consumer aspects for tomato quality grading. Computers and Electronics in Agriculture 31 (1), 17-29.

Jain, S., 2003. A survey of laser range finding. <http://awargi.org/ee236a.pdf>. (accessed 15.03.08)

Jarimopas, B., Siriratchatapong, P., Chaiyaboonyathanit, T., Niemhom, S., 1991. Image-processed mango sizing machine. Kasetsart Journal 25 (5), 131-139.

Jordan, R.B., Clark, C.J., 2004. Sorting of kiwifruit for quality using drop velocity in water. Transactions of the ASAE 47 (6), 1991-1998.

Kanali, C., Murase, H., Honami, N., 1998. Three-dimensional shape recognition using a charge-simulation method to process primary image features. Journal of Agricultural Engineering Research 70 (2), 195-208.

Kato, K., 1997. Electrical density sorting and estimation of soluble solids content of watermelon. Journal of Agricultural Engineering Research 67 (2), 161-170.

Laing, A., Smit, Q., Mortimer, B.J.P., Tapson, J., 1995. Ultrasonic fruit sizing device. Journal of the South African Acoustics Institute 6, 60-65

Lathulière, A., Mansouri, A., Voisin, Y., Marzani, F.S., Gouton, P., 2006. Stereoscopic system for $3-D$ reconstruction using multispectral camera and LCD projector. The Imaging Science Journal $54(1), 19-28$

Lee, D.J., Eifert, J., Zhan, P., Westover, P., 2003. Fast surface approximation for volume and surface area measurements using distance transform. Optical Engineering $42(10), 2947-2955$.

Lee, D.-J., Lane, R.M., Chang, G.H., 2001. Three-dimensional reconstruction for highspeed volume measurement. SPIE Machine Vision and Three-Dimensional Imaging Systems for Inspection and Metrology, vol. 4189, Boston, Mass., USA, pp. 258-267.

Lee, D.J., Xu, X., Eifert, J., Zhan, P., 2006. Area and volume measurements of objects with irregular shapes using multiple silhouettes. Optical Engineering 45 (2), 027202 .

Maisl, M., Kasperl, S., Oeckl, S., Wolff, A., 2006. Process monitoring using three dimensional computed tomography and automatic image processing. In: Proceedings of the 9th European Conference on Non-Destructive Testing. <www.ndt.net/article/ecndt2006/doc/We.3.7.1.pdf>. (accessed 23.01.08).

Marchant, J.A., 1990. A mechatronic approach to produce grading. In: Proceedings of the Institution of Mechanical Engineers, International Conference. Mechatronics: Designing Intelligent Machines, pp. 159-164.

Marchant, J.A., Onyango, C.M., Elipe, E., 1989. Weight and dimensional measurements on potatoes at high speed using image analysis. In: Sagaspe, J.P., Villeger, A. (Eds.), Agrotique 89: Proceedings of the Second International Conference, Teknea, pp. 41-52

Mattone, R., Campagiorni, G., Galati, F., 2000. Sorting of items on a moving conveyor belt. Part 1: a technique for detecting and classifying objects. Robotics and Computer Integrated Manufacturing 16 (2), 73-80.

Miller, W.M., 1987. Automated inspection/classification of fruits and vegetables. Transactions of the 1987 Citrus Engineering Conference, vol. 33. American Society of Mechanical Engineers, pp. 42-52.

Miller, W.M., 1990. An assessment of computer-based and conventional sizing of Florida tangerines. In: Food Processing Automation: Proceedings of the 1990 Conference. ASAE Publication 02-90: ASAE, St. Joseph, Mich., USA, pp. 235-243.

Miller, W.M., 1992. Packing density. Packinghouse Newsletter, 167, 1-2. IFAS, University of Florida.

Miller, W.M., 1993. Evaluation of sizer technologies for Florida Citrus. Proceedings of the Florida State Horticultural Society 106, 246-248.

Miller, W.M., Peleg, K., Briggs, P., 1988. Automated density separation for freezedamaged citrus. Applied Engineering in Agriculture 4 (4), 344-348.

Miller, W.M., Drouillard, G.P., 2001. Multiple feature analysis for machine vision grading of Florida citrus. Applied Engineering in Agriculture 17 (5), 627633.

Mitchell, P.D., 1986. Pear fruit growth and the use of diameter to estimate fruit volume and weight. HortScience 21 (4), 1003-1005. 
Mohsenin, N.N., 1970. Chapter 3: physical characteristics. Physical Properties of Plant and Animal Materials, vol. I. Gordon \& Breach Science Publishers Inc., New York, pp. 51-87.

Moreda, G.P., 2004. Diseño y evaluación de un sistema para la determinación en línea del tamaño de frutas y hortalizas mediante la utilización de un anillo óptico. Ph. D. Dissertation. Universidad Politécnica de Madrid, Spain. (Design and assessment of a system for on-line size determination of fruits and vegetables, using an optical ring sensor).

Moreda, G.P., Ortiz-Cañavate, J., Garcia-Ramos, F.J., Homer, I.R., Ruiz-Altisent, M. 2005. Optimal operating conditions for an optical ring sensor system to size fruits and vegetables. Applied Engineering in Agriculture 21 (4), 661-670.

Moreda, G.P., Ortiz-Cañavate, J., García-Ramos, F.J., Ruiz-Altisent, M., 2007. Effect of orientation on the fruit on-line size determination performed by an optical ring sensor. Journal of Food Engineering 81 (2), 388-398.

Ngouajio, M., Kirk, W., Goldy, R., 2003. A simple model for rapid and nondestructive estimation of bell pepper fruit volume. HortScience 38 (4), 509-511.

Nicolai, B.M., Beullens, K., Bobelyn, E., Hertog, M.L.A.T.M., Schenk, A., Vermeir, S., et al. 2006. Systems to characterize internal quality of fruit and vegetables. In: Proceedings of the IVth International Conference on Managing Quality in Chains - the Integrated View on Fruits and Vegetables Quality. Acta Horticulturae, vol. 712 , ISHS.

Nishizu, T., Ikeda, Y., Torikata, Y., Manmoto, S., Umehara, T., Mizukami, T., 2001. Automatic, continuous food volume measurement with a Helmholtz resonator. The CIGR Journal of Scientific Research and Development (e-journal). <http:// cigr-ejournal.tamu.edu/submissions/volume3/FP\%2001\%20004.pdf $>$. (accessed 03.09.07).

Njoroge, J.B., Ninomiya, K., Kondo, N., Toita, H., 2002. Automated Fruit Grading System Using Image Processing. SICE 2002. IEEE, Los Alamitos, Cal., USA.

Peleg, K., 1985a. Chapter 5: sorting operations. In: Produce Handling, Packaging and Distribution. AVl Publishing Co., Westport, Conn., pp. 53-87.

Peleg, K., 1985b. Chapter 6: Automatic sorting machines. In: Produce Handling, Packaging and Distribution. AVI Publishing Co., Westport, Conn., pp. 89-133.

Peleg, K., 1995. Automated packinghouse for fruits and vegetables. In: Proceedings of the ASAE-AMIA International Conference on Harvest and Postharvest Technologies for Fresh Fruits and Vegetables. Guanajuato, Mexico, pp. 143-151.

Poussart, D., Laurendeau, D., 1989. Chapter 3: 3-D sensing for industrial computer vision. In: Sanz, J.L.C. (Ed.), Advances in Machine Vision. Springer-Verlag Inc., New York, NY, pp. 122-159.

Sabliov, C.M., Boldor, D., Keener, K.M., Farkas, B.E., 2002. Image processing method to determine surface area and volume of axis-symmetric agricultural products. International Journal of Food Properties 5 (3), 641-653.

Sakai, N., Yonekawa, S., 1992. Three-dimensional image analysis of the shape of soybean seed. Journal of Food Engineering 15 (3), 221-234.

Sargent, S.A., Brecht, J.K., Talbot, M.T., Miller, W.M., Chau, K.V., 1988. Performance of packing line sizers for fresh market tomatoes. ASAE Paper No. 886590. St. Joseph, Mich., ASAE.

Sarkar, N., Wolfe, R.R., 1985. Feature extraction techniques for sorting tomatoes by computer vision. Transactions of the ASAE 28 (3), 970-979.

Shawver, B.M., Henderson, J.M., 1973. Undulating-surface singulator. Transactions of the ASAE $16(5), 934-935$.
SICK IVP AB. Smart camera IVC-3D. Wallenbergs gata 4. SE-583 35. Linköping Sweden. <www.sickivp.com/sickivp/products/smart_cameras/ivc/en.htmls. (accessed 04.03.08).

Strat, A.V., Oliveira, M.M., 2003. A point-and-shoot color 3D camera. In: Proceedings of the Fourth International Conference on 3-D Digital Imaging and Modeling (3DIM'03). IEEE.

Studman, C.J., 1999. Chapter 3: fruits and vegetables, section 3.3: handling systems and packaging. In: CIGR Handbook of Agricultural Engineering. vol. IV. ASAE, St. Joseph, Mich., USA, pp. 291-339.

Studman, C.J., 2001. Computers and electronics in postharvest technology - a review. Computers and Electronics in Agriculture 30 (1-3), 109-124.

Sugiura, T., Kuroda, H., Ito, D., Honjo, H., 2001. Correlations between specific gravity and soluble solids concentration in grape berries. Journal of the Japanese Society for Horticultural Science $70(3), 380-384$.

Sun, C., Berman, M., Coward, D., Osborne, B., 2007. Thickness measurement and crease detection of wheat grains using stereo vision. Pattern Recognition Letters 28 (12), 1501-1508.

Thomson, W.H., Pomeranz, Y., 1991. Classification of wheat kernels using threedimensional image analysis. Cereal Chemistry 68 (4), 357-361.

Throop, J.A., Rehkugler, G.E., Upchurch, B.L., 1989. Application of computer vision for detecting watercore in apples. Transactions of the ASAE 32 (6), 2087-2092.

Ting, S.V., Blair, J.G., 1965. The relation of specific gravity of whole fruit to the internal quality of oranges. Proceedings of the Florida State Horticultural Society $78,251-260$.

Torregrosa, A., Ortí, E., 1999. Mecanización de centrales y avances en el diseño de líneas de manipulación de cítricos. (Packinghouses mechanization and advances in citrus packing-lines design). Levante Agrícola, especial postcosecha, pp. 296-299.

Varghese, Z., Morrow, C.T., Heinemann, P.H., Joseph Sommer III, H., Tao, Y. Crassweller, R.M., 1991. Automated inspection of golden delicious apples using color computer vision. ASAE Paper No. 917002. St. Joseph, Mich., USA: ASAE.

Walsh, K.B., 2005. Commercial adoption of technologies for fruit grading, with emphasis on NIRS. FRUTIC '05 (Information and Technologies for Sustainable Fruit and Vegetable Production). Montpellier, France, pp. 399-408.

Wardowski, W.F., Miller, W.M. Grierson, W, 1998. Separation and grading of freeze-damaged citrus fruits. Circular 372. Florida Cooperative Extension Service, \& IFAS, University of Florida.

Wechsler, H., 1981. A new and fast algorithm for estimating the perimeter of objects for industrial vision tasks. Computer Graphics and lmage Processing 17 (4), 375-385.

Wright, M.E., Tappan, J.H., Sistler, F.E., 1986. The size and shape of typical sweet potatoes. Transactions of the ASAE 29 (3), 678-682.

Wu, J., Tillet, R., McFarlane, N., Ju, X., Siebert, J.P., Schofield, P., 2004. Extracting the three-dimensional shape of live pigs using stereo photogrammetry. Computers and Electronics in Agriculture 44 (3), 203-222.

Yang, D.K.M., 1996. Shape from darkness under error. Ph.D. thesis. Columbia University. <http://citeseer.ist.psu.edu/cache/papers/cs/17048/ftp:zSzzSzftp.cs. columbia.eduzSzpubzSzd-yangzSzthesis.pdf/yang96shape.pdf>. (accessed 18.02.08). 